\title{
Copyright
}

by

Lionel Herve Noel Ribeiro

2012 
The Report Committee for Lionel Herve Noel Ribeiro Certifies that this is the approved version of the following report:

\section{Multi-Phase Fluid-Loss Properties and Return Permeability of Energized Fracturing Fluids}

\section{APPROVED BY SUPERVISING COMMITTEE:}

Supervisor:

Mukul M. Sharma

Kamy Sepehrnoori 


\title{
Multi-Phase Fluid-Loss Properties and Return Permeability of Energized Fracturing Fluids
}

by

Lionel Herve Noel Ribeiro, Ingénieur Civil des Mines

\author{
Report \\ Presented to the Faculty of the Graduate School of \\ The University of Texas at Austin \\ in Partial Fulfillment \\ of the Requirements \\ for the Degree of
}

Master of Science in Engineering

The University of Texas at Austin

May 2012 


\section{Acknowledgements}

I would like to express my sincere gratitude to Dr. Mukul M. Sharma for his guidance and support throughout the duration of the research project. I have learnt a lot from him and I intend to carry the learning with me in every walk of like ahead. I also would like to thank Dr. Sepehrnoori for providing great suggestions in the modeling aspect of my research work and for reading this report. I owe many thanks to Dr. Kyle Friehauf (ConocoPhillips), who started the energized fracturing research at UT Austin, and Dr. Phil Harris (Halliburton), who set up the stage for foam leak-off research 30 years ago. They really inspired me to carry on this work.

I cannot thank enough Harry Linnemeyer, Glen Baum, and Tony Bermudez for helping me building up the experimental setup. It was a very tedious and challenging task, but it was also the most exciting part of my experimental work. I must also thank Jin Lee, whose dedication to the success of students is remarkable. They all greatly facilitated the multiple challenges of graduate school.

I am indebted to many of my friends and colleagues who shaped my research in so many ways. They made the graduate school journey enjoyable. In particular, I would like to thank Dr. Nicolas Roussel, Somnath Mondal, Sahil Malhotra, Mac Pedlow, Dr. David Torres, Corey McCulley, and Ripudaman Manchanda.

My family members and especially my parents have been a great inspiration and I would like to thank them for supporting me. This work is dedicated to them. 


\title{
Abstract \\ Multi-Phase Fluid-Loss Properties and Return Permeability of Energized Fracturing Fluids
}

\author{
Lionel Herve Noel Ribeiro, M. S. E. \\ The University of Texas at Austin, 2012
}

Supervisor: Mukul M. Sharma

With the growing interest in low-permeability gas plays, foam fracturing fluids are now well established as a viable alternative to traditional fracturing fluids. Present practices in energized fracturing treatments remain nonetheless rudimentary in comparison to other fracturing fluid technologies because of our limited understanding of multi-phase fluid-loss and phase behavior occurring in these complex fluids. This report assesses the fluid-loss benefits introduced by energizing the fracturing fluid.

A new laboratory apparatus has been specifically designed and built for measuring the leak-off rates for both gas and liquid phases under dynamic fluid-loss conditions. This report provides experimental leak-off results for linear guar gels and for $\mathrm{N}_{2}$-guar foam-based fracturing fluids under a wide range of fracturing conditions. In 
particular, the effects of the rock permeability, the foam quality, and the pressure drop are investigated. Analysis of dynamic leak-off data provide an understanding of the complex mechanisms of viscous invasion and filter-cake formation occurring at the pore-scale.

This study presents data supporting the superior fluid-loss behavior of foams, which exhibit minor liquid invasion and limited damage. It also shows direct measurements of the ability of the gas component to leak-off into the invaded zone, thereby increasing the gas saturation around the fracture and enhancing the gas productivity during flowback. Our conclusions not only confirm, but add to the findings of McGowen and Vitthal (1996) for linear gels, and the findings of Harris (1985) for nitrogen foams. 


\section{Table of Contents}

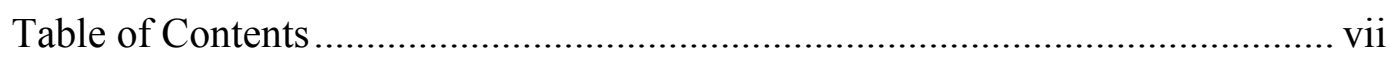

List of Tables ....................................................................................... ix

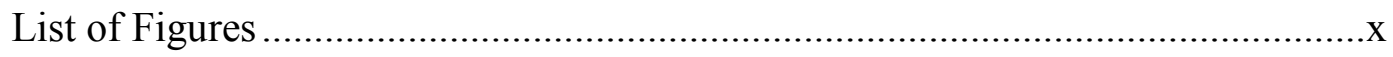

Chapter 1: Introduction .............................................................................. 1

Chapter 2: Critical Literature Review ............................................................4

2.1 Leak-off Literature Review...........................................................4

2.2 Effect of Multi-Phase Leak-off on Fracture Productivity ........................6

Chapter 3: Multi-Phase Leak-off Experimental Setup.....................................10

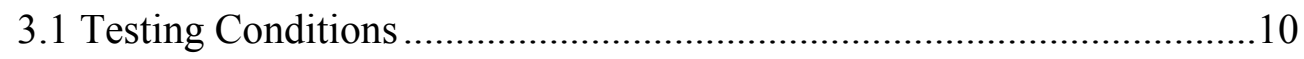

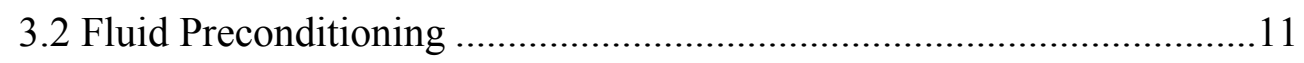

3.3 Fluid-Loss Cell............................................................................ 13

3.4 Dynamic Multi-Phase Leak-off Tests ............................................... 14

Chapter 4: Results and Discussion for Linear Gels .........................................20

4.1 Dynamic versus Static Leak-off Tests ................................................20

4.2 Effect of Pressure Drop...................................................................20

4.3 Effect of Core Permeability ...............................................................22

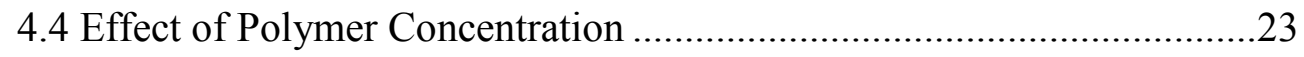

4.5 Effect of Shear Rate History ................................................................24

4.6 Comparison With Published Data......................................................24

Chapter 5: Results and Discussion for Nitrogen Foams ..................................29

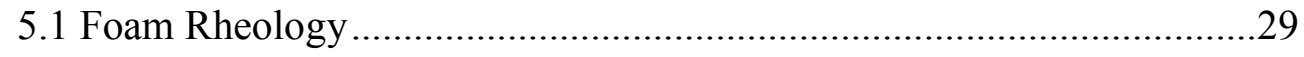

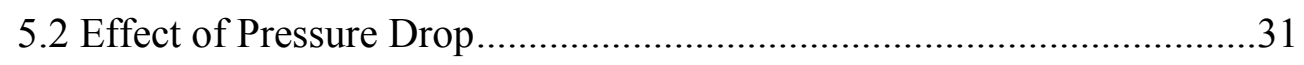

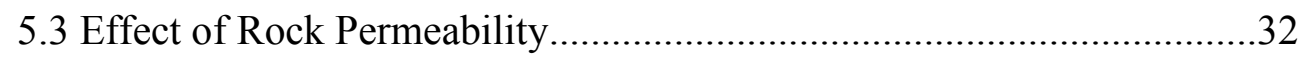

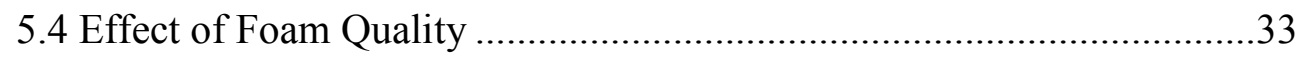

5.5 Comparison with Published Data............................................................34 


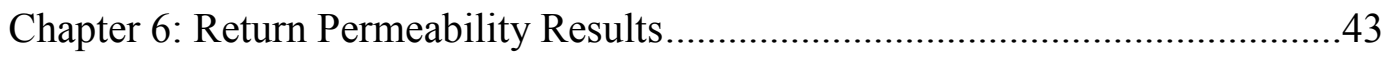

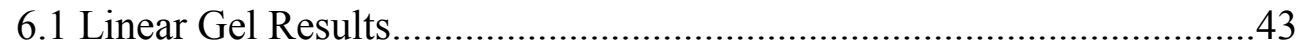

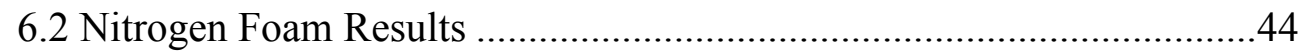

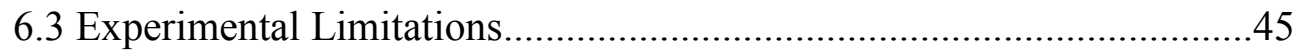

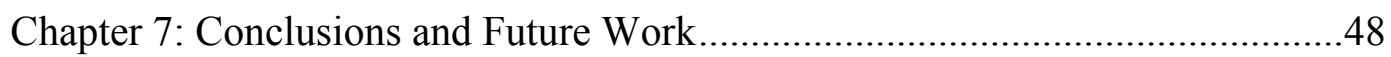

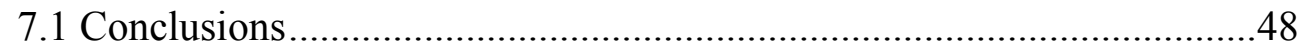

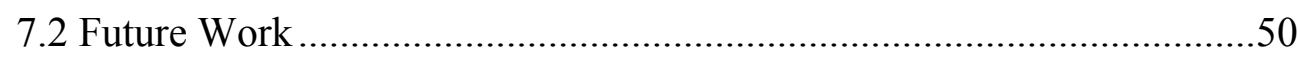

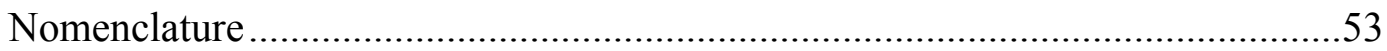

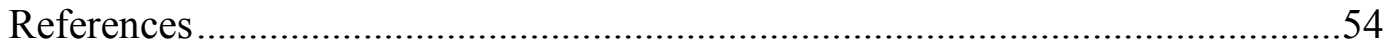




\section{List of Tables}

Table 2.1: Rheology correlations for nitrogen foams (Reidenbach et al., 1986)............... 8

Table 3.1: List of linear gel experiments presented in this report. ............................... 17

Table 3.2: List of nitrogen foam experiments presented in this report.......................... 17

Table 5.1: Comparison of foam leak-off data with published data............................... 37

Table 7.1: Effect of various parameters on fluid-loss................................................. 52 


\section{List of Figures}

Figure 2.1: Viscosity as a function of foam quality for $\mathrm{N}_{2}$ foam with $40 \mathrm{lb} / \mathrm{Mgal}$ loading

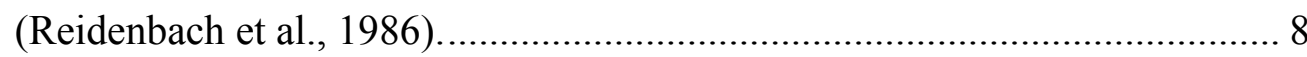

Figure 2.2: Productivity index vs. drawdown pressure for several fracturing fluids

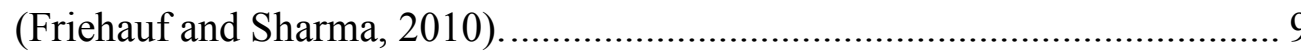

Figure 3.1: Simplified schematic of the foam-loop system, with relevant measurements

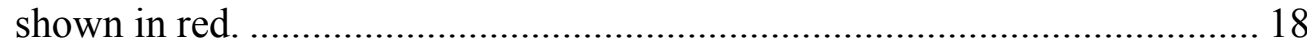

Figure 3.2: Drawing of the fluid-loss cell (courtesy of TEMCO).................................. 18

Figure 3.3: Drawing of the fluid-loss cell and the "equivalent" flow pattern in a thin,

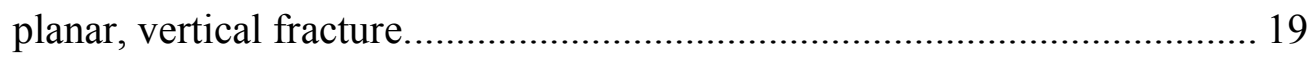

Figure 3.4: External filter-cakes observed after leak-off tests on Berea and Nugget sandstone samples.

Figure 4.1: Effect of pressure drop on 1.5-mD cores. …………................................... 26

Figure 4.2: Effect of rock permeability at $\Delta \mathrm{P}=1000 \mathrm{psi}$ (effluent volume).................... 26

Figure 4.3: Effect of rock permeability at $\Delta \mathrm{P}=1000 \mathrm{psi}$ (pressure profile). ................... 27

Figure 4.4: Effect of gel loading on 390-mD (effluent volume).................................... 27

Figure 4.5: Effect of gel loading on 390-mD (permeability profile) …………….......... 28

Figure 4.6: Effect of shear rate history. ..................................................................... 28

Figure 5.1: Pressure drop measured in the foam loop over time. ................................... 37

Figure 5.2: Foam viscosity versus shear rate for multiple foam qualities. ...................... 38

Figure 5.3: Comparison of foam viscosity measurements at a shear rate of $100 \mathrm{~s}^{-}{ }^{1} \ldots \ldots . . .38$ 
Figure 5.4: Effect of pressure drop on liquid and gas effluents for 1.5-mD cores.

Figure 5.5: Effect of pressure drop on foam effluent for $390-\mathrm{mD}$ cores. ........................ 39

Figure 5.6: Effect of rock permeability on fluid effluents for cores exposed at 500 psi. . 40

Figure 5.7: Effect of foam quality on liquid/gas leak-off for 55-mD cores under a 500-psi pressure drop. 40

Figure 5.8: Effect of foam quality on liquid/gas leak-off for 1.5-mD cores under a 1000psi pressure drop 41

Figure 5.9: Effect of foam quality on the liquid leak-off coefficient............................ 41

Figure 5.10: Effect of foam quality on the gas leak-off coefficient............................. 42

Figure 5.11: Outlet composition enriched in the liquid phase as the result of filtration... 42

Figure 6.1: Return permeability results for linear guar gel experiments. 47

Figure 6.2: Return permeability results for $\mathrm{N}_{2}$ foam experiments. 47 


\section{Chapter 1: Introduction}

The rate of fluid leak-off to the rock formation is one of the most critical parameters involved in fracture design. The fluid invasion directly affects the fracture geometry, the fracture closure time, and the final proppant distribution. The fracture productivity is largely related to the amount of liquid placed around the fracture. If an operator overestimates the leak-off rate, the pumping rate may be unnecessary high and may cause excessive pump pressures. Alternatively, an operator is likely to lower the pumping rate if he underestimates the leak-off rate. In this case, the fracturing fluid may not be able to propagate large quantities of proppant along the fracture. As the proppant accumulates and the frictional pressure drop in the fracture increases, a premature screenout is likely to occur. This results in a premature job termination with a fracture that is shorter than expected.

The petroleum literature contains numerous experimental studies on the leak-off behavior of linear gels, and the reader may refer to the summaries compiled by Penny and Conway (1989) or McGowen and Vitthal (1996). However, very little data is available for multi-phase fluids. Harris conducted the only systematic, published, multi-phase leak-off study on $\mathrm{N}_{2}$ (Harris 1985) and $\mathrm{CO}_{2}$ foams (Harris 1987).

Despite the lack of fluid-loss data, foam-based fluids have been successfully used since the mid-70s (Grundman 1983). They are now routinely used in low-permeability and depleted reservoirs where the drawdown forces are not sufficient to recover any fracturing fluid that invades the formation (Wendorff and Ainley 1981). Foams are also

used in water-sensitive formations where clay swelling is a significant issue (Gabris and Taylor 1986; King 1986). 
Over the past couple of years, the use of energized fluids has significantly increased. The recent push for "waterless" fracture treatments was motivated either (1) by the economics, or by (2) limited water availability. In some reservoirs, energized fluids significantly outperform traditional water fractures. As evidenced by some economic analysis (Burke and Nevison 2011), the incremental production can be sufficient to cover the incremental cost of using energized fluids. In some other cases, operators used energized treatments simply because (1) the volume of water available was limited, (2) the water quality was not compatible with the chemicals, or (3) some legislation prohibited the usage of large water quantities.

By using foams, operators reduce the amount of water placed in the rock formation, which in turn minimizes the contact area between water and water-sensitive material. This being said, water-based foams do not eliminate the clay-swelling problem, and oil-based fracturing fluids may be preferred in case of severe clay swelling issues. The three most obvious advantages of foams are: (1) limiting the amount of liquid placed in the rock matrix (thereby minimizing liquid blocking), (2) improving the fluid recovery (due to the presence of free gas and soluble gas coming out of solution), and (3) minimizing the contact between water and water-sensitive clays and fines.

This report presents the first systematic experimental study of multi-phase fluidloss for fracturing fluids under dynamic conditions. We introduce a new experimental apparatus with the unique capability of combining foam rheology and dynamic leak-off measurements over time. The report shows the superior fluid-loss behavior of energized fluids.

The report is divided in 7 chapters. Chapter 1 introduces the motivation behind this work. Chapter 2 reviews the leak-off literature for both linear gels and foams. 
Chapter 3 presents the laboratory apparatus and the laboratory protocols. Chapter 4 contains the leak-off results for linear gels. Chapter 5 contains the leak-off results for nitrogen foams. Chapter 6 compares the performance of linear gels and nitrogen foams. Chapter 7 presents the conclusions of this study and future work. 


\section{Chapter 2: Critical Literature Review}

\subsection{LEAK-OFF LITERATURE REVIEW}

A Conventional leak-off analysis (Penny and Conway 1989; McGowen and Vitthal 1996) involves the use of a leak-off coefficient $\left(C_{w}\right)$, which represents the flow resistance associated with the complex filtration process occurring at or near the fracture face. $\mathrm{C}_{\mathrm{w}}$ depends on the fracturing fluid properties and on the pore size distribution of the rock formation. In traditional filtration theory, $\mathrm{C}_{\mathrm{w}}$ is obtained experimentally from the slope of the cumulative filtrate volume versus square root of time as described by Equation (2.1). In practice, $\mathrm{C}_{\mathrm{w}}$ is the slope of the experimental plot of filtrate volume versus the square root of time (m), divided by the cross-sectional area of the exposed core, as shown in Equation (2.2). The filtrate volume obtained before establishment of a competent filter-cake is referred to as spurt-loss volume (VSL). It is obtained as the yintercept of the linear trend attained at later times.

$$
\begin{gathered}
V=V_{S L}+2 C_{w} \sqrt{t} \\
C_{w}=0.0164 \times \mathrm{m} / \mathrm{A}_{c}
\end{gathered}
$$

Harris $(1985,1987)$ measured fluid-loss properties of $\mathrm{N}_{2}$ and $\mathrm{CO}_{2}$ foams. He showed that foams can break down when the rock permeability is low enough. This results in the invasion of liquid filtrate and gas at different rates. His research advocated the use of foams as they exhibited lower leak-off and insignificant damage. The main limitation of his work was the use of an impinging fluid leakoff cell that did not allow proper circulation of the fracturing fluid near the core face. 
At high foam quality (gas volume fraction), interactions between bubbles cause energy dissipation resulting in a high effective viscosity (Economides 2000). The internal phase remains stable until very high qualities are reached $(\sim 95 \%)$. Then, the gas becomes the external phase and the mixture is referred to as a mist. The foam stability is the result of the quasi-equilibrium between buoyancy and inertial forces, which favors gas bubble coalescence, and the shear force, which dynamically breaks the gas bubbles and mixes them with the internal phase. At low qualities (typically around $50 \%$ ), the interactions between bubbles are minimal so the fluid viscosity resembles that of the base fluids.

Reidenbach et al. (1986) studied the rheology of foams under laminar and turbulent flow conditions. He described the $\mathrm{N}_{2}$-foam rheology with a Herschel-Buckley model that is a function of foam quality, gas type, and base-fluid rheology. The model includes the Herschel-Bulkley parameters $(\tau, \mathrm{n}$, and $\mathrm{K}$ ) and an empirical correlation value, $\mathrm{C}_{1}$, which depends on the gel loading (Table 2.1). His formulation is given in Equation (2.3) and his experimental results are provided in Figure 2.1.

$$
\left\{\begin{array}{l}
\tau_{\text {foam }}=0.07 \Gamma \text { if } \Gamma \leq 0.6 \\
\tau_{\text {foam }}=0.0002 e^{9 \Gamma} \text { if } \Gamma>0.6
\end{array} \quad ; \quad n_{\text {foam }}=n_{0} \quad ; \quad K_{\text {foam }}=K_{0} \exp \left(C_{1} \Gamma+0.75 \Gamma^{2}\right)\right.
$$

Although Reidenbach et al. (1986) suggested that the foam viscosity increases very steeply at a quality of $52 \%$, it should be noted that this value depends on the surfactants and gelling agents used. It is possible to generate higher viscosity foams at lower qualities when using different base-fluid formulations and foaming agents. The quality for which foam becomes mist is also dependent of the base-fluid formulation. 


\subsection{Effect of Multi-Phase Leak-off on Fracture Productivity}

Friehauf and Sharma $(2009,2010)$ have recently included the effects of multiphase leak-off into the very first compositional fracturing simulator. In their model, each phase has its own leak-off properties, and the leak-off term is used in a specific mass balance for each component. Their fracturing simulator encompasses a well productivity model that is capable of evaluating the flowback performance of multi-phase systems. Figure 2.2, taken from Friehauf and Sharma (2010), shows the productivity index versus the drawdown pressure for four fracturing treatments. The base productivity $\left(\mathrm{J}_{0}\right)$ refers to the productivity of an unfractured, undamaged, well in a circular drainage area. The drawdown pressure is the difference between the reservoir pressure and the flowing bottom-hole pressure. In this example, they assume that (1) the free gas phase does not leak-off into the formation during fracturing; (2) there is no shut-in period at the end of the pumping (forced closure); and (3) the reservoir is initially at residual water saturation. Under these conservative assumptions, the gas phase can invade the reservoir only because of solubility.

As indicated by Figure 2.2, the drawdown forces were not sufficient to overcome the capillary forces for pressures lower than the reservoir capillary pressure (320 psi for a 0.01- $\mathrm{mD}$ reservoir). As a result, the liquid phase that leaked-off remained trapped, and impeded the gas production because of relative permeability effects. For pressures higher than the reservoir capillary pressure, most of the liquid was recovered during flowback and the treatment was beneficial. Under the given conditions of pressure and temperature, the nitrogen solubility is negligible. Therefore, no gas is introduced into the porous medium and the nitrogen foam treatment does not outperform the traditional linear gel treatment. Alternatively, carbon dioxide is appreciably more soluble in water under the given conditions. The release of soluble gas significantly stimulated the 
invaded zone. For pressures below $320 \mathrm{psi}$, the difference in performance between $\mathrm{CO}_{2}$ and $\mathrm{N}_{2}$ foam treatments was entirely explained by the difference in solubility between $\mathrm{CO}_{2}$ and $\mathrm{N}_{2}$ since we assumed that the free gas leak-off was zero in both cases. If the free gas leak-off was non-zero, these conclusions would be dramatically changed. Predicting the ability of the free gas to leak-off is thus critical when designing energized treatments. 
Table 2.1: Rheology correlations for nitrogen foams (Reidenbach et al., 1986).

\begin{tabular}{|cccc|}
\hline HPG Load (lb/Mgal) & $\mathbf{n ~ ( - )}$ & $\mathbf{K}\left(\mathbf{l b f}-\mathbf{s e c}^{\mathbf{n}} / \mathbf{f t}^{\mathbf{2}}\right)$ & $\mathbf{C}_{\mathbf{1}} \mathbf{( - )}$ \\
\hline 0 & 1 & 0.00002 & 3.6 \\
10 & 0.75 & 0.0053 & 2.1 \\
20 & 0.607 & 0.00256 & 1.7 \\
40 & 0.45 & 0.0152 & 1.2 \\
\hline
\end{tabular}

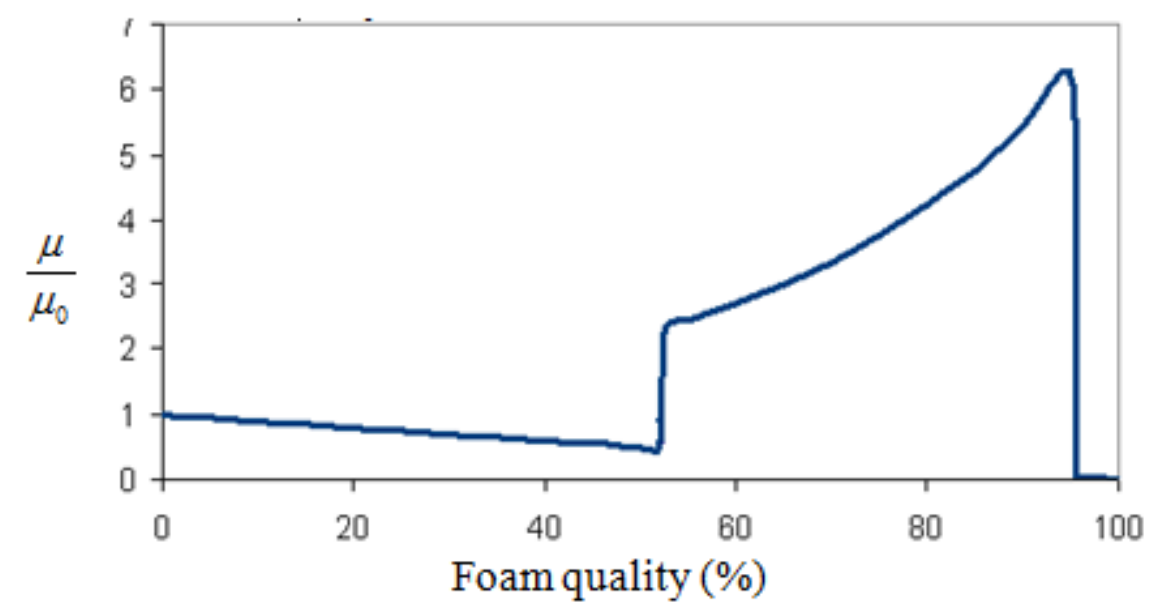

Figure 2.1: Viscosity as a function of foam quality for $\mathrm{N}_{2}$ foam with $40 \mathrm{lb} / \mathrm{Mgal}$ loading (Reidenbach et al., 1986). 


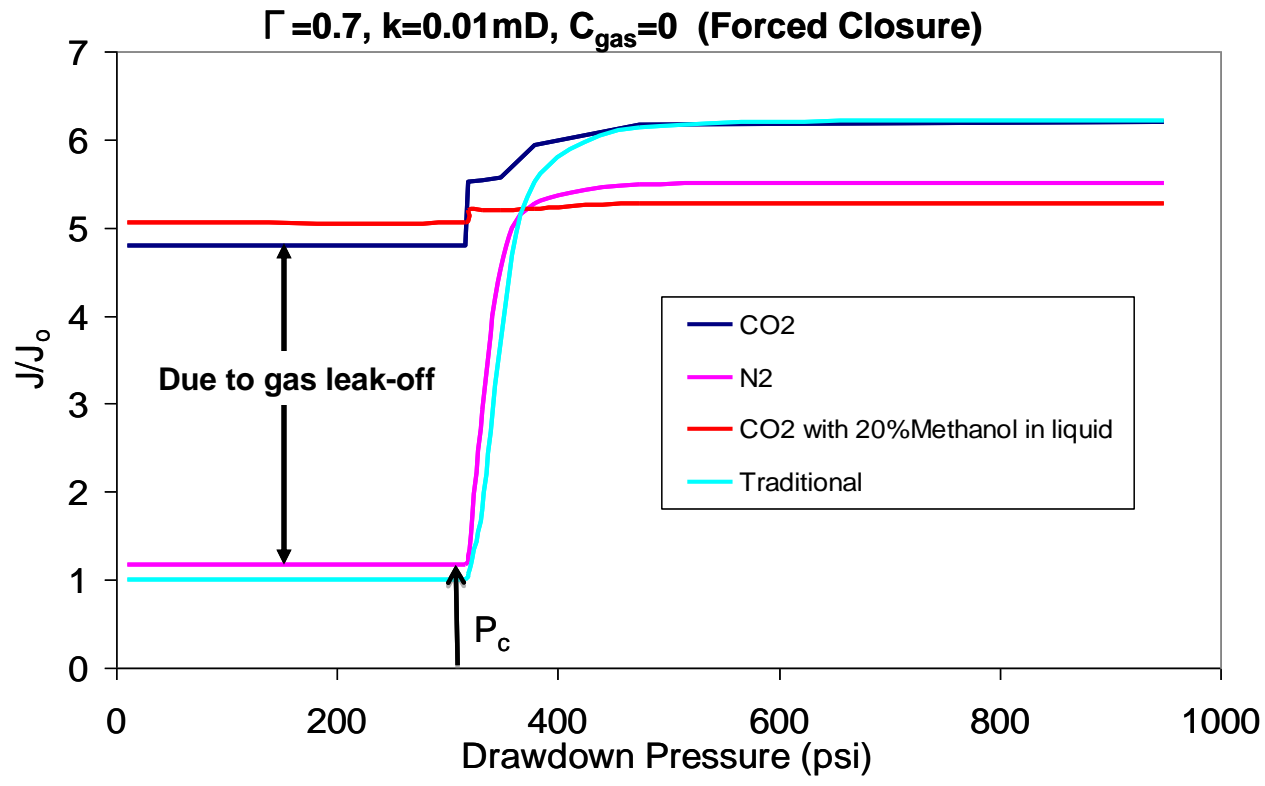

Figure 2.2: Productivity index vs. drawdown pressure for several fracturing fluids (Friehauf and Sharma, 2010). 


\section{Chapter 3: Multi-Phase Leak-off Experimental Setup}

\subsection{Testing Conditions}

A new laboratory apparatus has been designed and built for evaluating the performance of foam fracturing fluids (Ribeiro and Sharma 2011). The setup enables us to (1) measure the dynamic leak-off rates of both the liquid and gas phases, (2) measure the foam rheology and stability over time, and (3) evaluate the rock regain permeability during flowback. The unique feature of this apparatus is to combine multi-phase fluidloss and rheology measurements. A simplified schematic of the system is provided in Figure 3.1. It consists of an 850-cc closed-loop system in which the fluid is prepared and circulated at fracturing conditions. The foam-loop includes a foam generator, which is an in-line screen, a circulating pump (high flow-rate gear pump), and a mass flowmeter. Gas and liquid are loaded separately to the loop through the use of backpressure and reducing regulators (denoted by $\mathrm{BPR}$ and $\mathrm{RR}$, respectively). The loop is connected to the fluid-loss cell that contains the formation core.

All the experiments presented in this report were performed for at least 90 minutes at ambient temperature (about $80^{\circ} \mathrm{F}$ ) with a dynamic filtration core holder (Figure 3.2). Unless otherwise stated, the shear rate was maintained at about $40 \mathrm{~s}^{-1}$ for the tests with linear gels and at about $20 \mathrm{~s}^{-1}$ for the tests with foams. The cores were 1inch in diameter by 3 -inches long. The pressure drop (which is here the differential pressure between the core inlet and the core outlet) ranges from 450 to 1500 psi. Fluid type and fluid composition were varied to cover a wide range of fracturing conditions. Tables 3.1 and 3.2 detail the testing conditions for each experiment presented in this report. 
Various Berea and Nugget sandstone samples, ranging from 1 to $400 \mathrm{mD}$, were used to evaluate the effects of the rock permeability. These sandstone cores were chosen because they have a high compressive strength and are quite homogenous. Sandstone cores were preferred over limestone cores to limit flow irregularities resulting from secondary porosity. The cores were dried, vacuumed, and wrapped with Teflon tape and heat shrink tubing to avoid leakage during the experiment. Cores were initially presaturated with $3 \%$ potassium chloride brine. Prior to foam experiments, the cores were also extensively flooded with nitrogen to reach residual water saturation. Nevertheless, we typically did not reach the true residual water saturation before starting the leak-off test.

The leak-off tests presented here were conducted at ambient temperature and with a back pressure set to zero (the pressure at the core outlet was atmospheric). Therefore, the foam leak-off results of this study may not be quantitatively correct under reservoir conditions. However, the underlying mechanisms of leakoff and the overall trends and conclusions should remain valid.

\subsection{Fluid Preconditioning}

The base fluid for both linear gels and nitrogen foams was a blend of guar powder mixed with a $3 \%$ by weight potassium chloride solution. Guar powder was mixed for an hour at a moderately high shear rate to attain proper hydration. The base-fluid rheology was measured using a traditional Fann viscometer. Readings were consistent from one batch to another. The guar solution was loaded into the foam loop at the desired pressure with the loading pump indicated in Figure 3.1. The loading pump is a high-pressure syringe pump. A second pump, referred to as the circulating pump, maintained a 
constant flow rate at the desired pressure. This pump was a high flow rate gear pump capable of circulating mixtures of gas and liquid.

For foam experiments, surfactants (foamers) were added to lower the surface tension between the internal gas phase and the external liquid phase. Nitrogen was added to the closed-loop by proper use of reducing and backpressure regulators, denoted by RR and BPR in Figure 3.1, respectively. The nitrogen was first loaded to a 3-liter accumulator pressurized at a pressure slightly above the loop pressure. A BPR was connected to the loop exit to ensure constant pressure within the loop. A RR was connected at its upstream side to the nitrogen accumulator and at its downstream side to the loop. By applying a pressure at the RR slightly above the BPR pressure, the gas slowly displaced the base-fluid initially present in the loop. The volume of liquid coming out of the loop was monitored to keep track of the volume of gas loaded to the loop at the pressure of interest. Once a small amount of liquid was displaced (typically $50 \mathrm{cc}$ ), the circulating pump was run at high speed to promote turbulent mixing through the foam generator (in-line screen). This process was repeated step-by-step to safely ensure foam mixing. The foam quality increases at each step, as some gas displaces some of the liquid phase. At any time, the foam quality was calculated from the density measurements indicated by the mass flowmeter. The density of the foam was simply the weighted average of the gas and liquid densities, which were both well-known. The gas loading was stopped once a specific foam density was achieved. For instance, a density of 0.43 $\mathrm{g} / \mathrm{cc}$ indicated a nitrogen foam quality of $60 \%$ at $1000 \mathrm{psi}$.

The foam flow rate and the pressure drop across a tubing of known dimensions were monitored over the duration of the leak-off test. The differential pressure transducer recording the pressure drop is referred to as rheometer in Figure 3.1. The mixture was 
circulated at a constant shear rate until stable readings of density and viscosity were obtained over time. A high-pressure view cell was also used to provide visual inspection of the foam texture. Our rheology setup is comparable to the apparatus introduced by Hutchins and Miller (2005), who evaluated foam viscosity and stability over time with a circulating pipe (Figure 5 and Table 1 of Hutchins and Miller, 2005). We adopted a very similar approach in terms of foam generation, circulation, and rheology characterization. Our apparatus allows us to not only measure the foam viscosity and the foam quality over time, but also to measure the dynamic leak-off rate simultaneously.

\subsection{FLUID-Loss CELL}

The fluid-loss cell is a Hassler-type core holder with a special end-design allowing for dynamic testing of fluid invasion into core samples, as shown in Figure 3.2. With conventional core holders, the flow injection is parallel to the core. Instead, we used a core holder with a flow-through slot that allows us to flow the fracturing fluid in the direction perpendicular to the core face; the core face being simply exposed to the fracturing fluid. Figure 3.3 shows a schematic of the narrow flow conduit within the fluid-loss cell. In this figure, the end-cap is grey; the flow-through slot is blue; and the core is brown. This specific flow pattern is intended to mimic the flow path experienced by the fracturing fluid within a thin, planar, fracture. The major flow direction is out of the plane. This major flow direction is indicated by the thicker arrows in Figure 3.2. The fluid leak-off occurs in the direction indicated by the thinner arrows in Figures 3.2 and 3.3 .

The shear rate at the core face was estimated from the fluid flow rate and the flow-through slot dimensions. In this report, the shear rate provided for the leak-off experiments refers to the shear rate of the fluid in the flow-through slot (facing the core 
inlet). The shear rate provided in the foam rheology section refers to the shear rate within the tubing. To be consistent, the same shear rate should be experienced throughout the foam loop. This is hard to achieve because of the numerous perturbations introduced by the valves and the in-line equipment. This being said, we chose a tubing size that gave us a shear rate similar to the one in the slot. Equations (3.1) and (3.2) give the shear rate expressions for the fluid flowing inside the flow-through slot and in the tubing, respectively:

$$
\begin{gathered}
\gamma_{\text {slot }}=\frac{6 v}{w}=\frac{0.1 \times q}{w^{2} \times h} \\
\gamma_{\text {tubing }}=\frac{8 v}{I D}=\frac{8 \times q}{15 \pi \times I D^{3}}
\end{gathered}
$$

In Equations (3.1) and (3.2), q refers to the volumetric flow rate imposed by the circulating pump and measured by the mass flowmeter (in $\mathrm{cc} / \mathrm{min}$ ); $\mathrm{v}$ refers to the average velocity (in $\mathrm{cm} / \mathrm{s}$ ); w refers to the slot width (in $\mathrm{cm}$ ); $\mathrm{h}$ refers to the slot height (in $\mathrm{cm}$ ); and ID refers to the tubing internal diameter (in $\mathrm{cm}$ ). In our setup, the slot width was $0.25 \mathrm{inch}$; the slot height was $0.75 \mathrm{inch}$; and the dimensions of the tubing were 0.5 -inch outside diameter with a wall thickness of 0.035 inch. For example, a flow rate of 300 $\mathrm{cc} / \mathrm{min}$ yields a shear rate of about $40 \mathrm{~s}^{-1}$ both in the flow-through slot and in the tubing.

\subsection{Dynamic Multi-Phase Leak-off Tests}

One-inch diameter cores were placed into an elastomeric sleeve that is subject to a radial confining stress applied with synthetic oil. Three pressure taps were placed along the core sample to monitor the extent of the fluid invasion process over time. Dynamic leak-off tests were performed for at least 90 minutes. During the leak-off test, the loading pump was operated under constant pressure to compensate for the amount of

fluid leaking-off. The loading pump added into the loop a volume of linear gel equal to 
the volume of fluid leaking-off in order to maintain a constant pressure in the loop during the entire the leak-off test.

For most experiments, the cumulative amount of fluid leak-off was negligible compared to the volume of the foam loop (about $850 \mathrm{cc}$ ), and the pressure was successfully maintained constant over time. This was always the case for foam experiments. Therefore, the addition of linear gel into the loop did not significantly affect the foam quality over time. In some experiments (conducted with linear gels on high-permeability cores), the initial leak-off rate was higher than the maximum flow rate of the loading pump $(28 \mathrm{cc} / \mathrm{min})$. As a result, the addition of linear gel could not compensate the amount of fluid lost through the core, and the pressure was not successfully maintained over time. An example of this is shown in Figure 4.3 for the 25$\mathrm{mD}$ and the $400-\mathrm{mD}$ cores.

In this report, the backpressure regulator was bypassed and the pressure at the core outlet was atmospheric. The pressure drop across the core was continuously monitored with a differential pressure transmitter connected to the core inlet and the core outlet. A high-accuracy weighing scale measured the weight of liquid effluent exiting the core over time. The gas effluent was collected at atmospheric pressure into a liquid-filled graduated cylinder. As the gas exited the core sample, it displaced the liquid out of the cylinder and the volume of gas was directly read from the graduations. The volume of nitrogen was then converted back from atmospheric to testing conditions to take into account the large gas expansion.

The use of linear gels as fracturing fluids has two adverse effects, related to the liquid filtrate invasion through the rock matrix and the deposition of polymer residues either at the core face or inside the rock matrix. Pictures of external filter-cake are given 
in Figure 3.4 for Berea (top pictures) and Nugget (bottom pictures) sandstone cores. These pictures show the establishment of a relatively thick filter cake on top of the core face exposed to the fracturing fluid. The thick, polymer-rich, filter-cake constitutes a low-permeability barrier that impedes the flow of gas or liquid during flowback. These pictures were taken at the end of the regain permeability tests, which implies that the flowback of gas and brine has not entirely removed the external filter-cake. The external filter-cake can constitute a long-term source of permeability damage. 
Table 3.1: List of linear gel experiments presented in this report.

\begin{tabular}{|cccccc|}
\hline Figure \# & Fluid Type & $\mathbf{\Delta P}(\mathbf{p s i})$ & $\mathbf{k}(\mathbf{m D})$ & $\mathbf{G e l}(\mathbf{l b m} / \mathbf{M g a l})$ & $\mathbf{C w}(\mathbf{f t} / \sqrt{\mathbf{m i n})}$ \\
\hline \multirow{4}{*}{4.1} & Guar & 550 & 1.5 & 30 & 0.0032 \\
& Guar & 1000 & 1.5 & 30 & 0.0033 \\
& Guar & 2000 & 1.5 & 30 & 0.0034 \\
\hline \multirow{3}{*}{4.2 and 4.3 } & Guar & 1000 & 1.5 & 30 & 0.0033 \\
& Guar & 1000 & 25 & 30 & 0.0178 \\
& Guar & 1000 & 390 & 30 & 0.055 \\
\hline \multirow{3}{*}{4.4 and 4.5 } & Guar & 550 & 390 & 20 & 0.051 \\
& Guar & 550 & 390 & 30 & 0.048 \\
& Guar & 550 & 390 & 40 & 0.055 \\
\hline
\end{tabular}

Table 3.2: List of nitrogen foam experiments presented in this report.

\begin{tabular}{|c|c|c|c|c|c|c|}
\hline Figure \# & $\Delta P(p s i)$ & $\mathbf{k}(\mathbf{m D})$ & $Y\left(s^{-1}\right)$ & $\Gamma$ & $\mathrm{Cw}_{\text {liquid }}\left(\mathrm{ft} / \sqrt{ }_{\mathrm{min}}\right)$ & $\mathbf{C} w_{\text {gas }}\left(\mathbf{f t} / \sqrt{ }_{\mathbf{m i n}}\right)$ \\
\hline \multirow{3}{*}{5.4} & 450 & 1.5 & 20 & 0.55 & 0.0008 & 0.0005 \\
\hline & 950 & 1.5 & 20 & 0.55 & 0.0021 & 0.0020 \\
\hline & 1400 & 1.5 & 20 & 0.55 & 0.0019 & 0.0019 \\
\hline \multirow{3}{*}{5.5} & 465 & 390 & 20 & 0.6 & 0.0089 & / \\
\hline & 800 & 390 & 20 & 0.6 & 0.0163 & I \\
\hline & 1250 & 390 & 20 & 0.6 & 0.0133 & 1 \\
\hline \multirow{3}{*}{5.6} & 500 & 1.5 & 20 & 0.6 & 0.0008 & 0.0005 \\
\hline & 500 & 55 & 20 & 0.6 & 0.0023 & 0.0019 \\
\hline & 500 & 390 & 20 & 0.6 & 0.0089 & / \\
\hline \multirow{4}{*}{5.7} & 500 & 55 & 20 & 0.25 & 0.0044 & 0.0005 \\
\hline & 500 & 55 & 20 & 0.5 & 0.0035 & 0.0025 \\
\hline & 500 & 55 & 20 & 0.55 & 0.0023 & 0.0019 \\
\hline & 500 & 55 & 20 & 0.65 & 0.0024 & 0.0024 \\
\hline \multirow{4}{*}{5.8} & 1000 & 1.5 & 20 & 0 & 0.0034 & 0 \\
\hline & 1000 & 1.5 & 20 & 0.4 & 0.0023 & 0.0008 \\
\hline & 1000 & 1.5 & 20 & 0.62 & 0.0021 & 0.0020 \\
\hline & 1000 & 1.5 & 20 & 0.68 & 0.0017 & 0.0011 \\
\hline
\end{tabular}




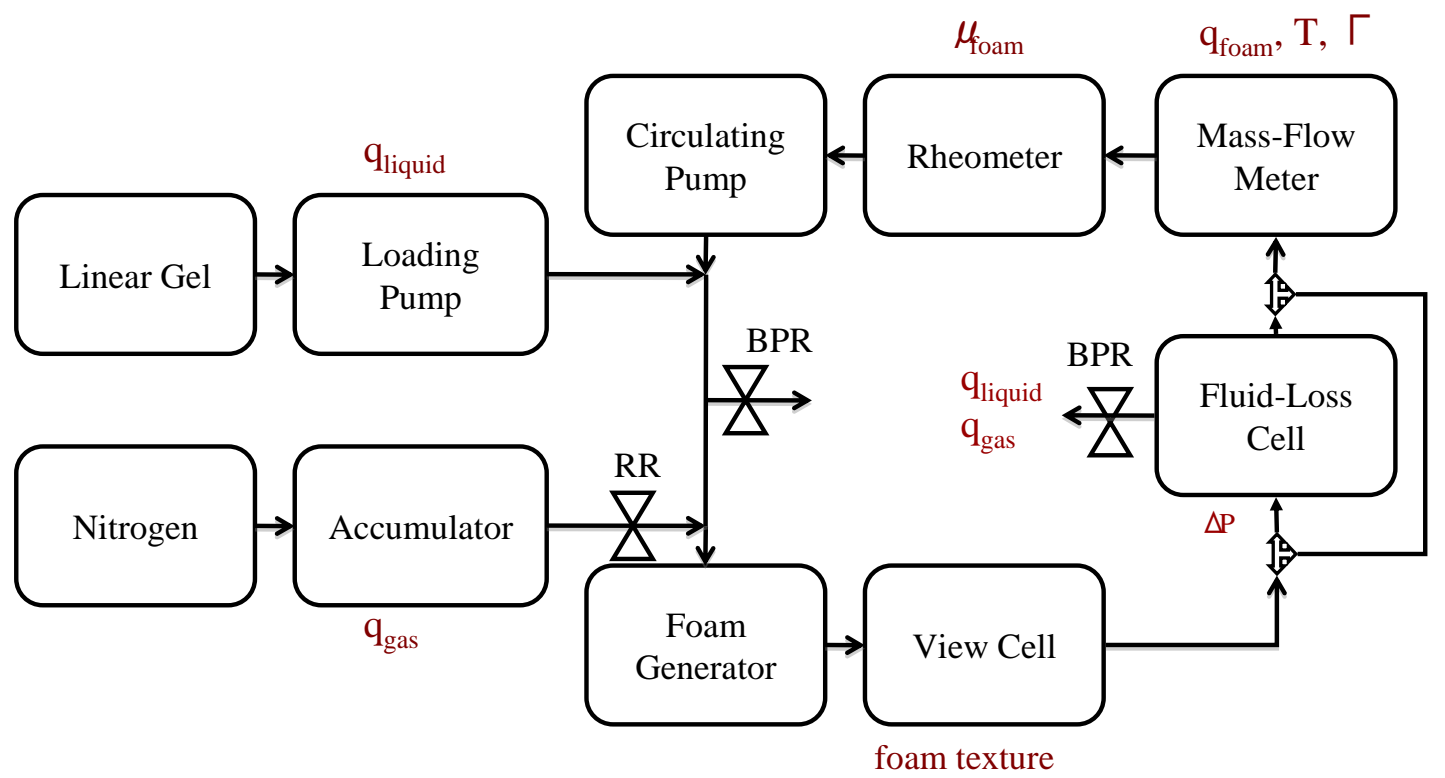

Figure 3.1: Simplified schematic of the foam-loop system, with relevant measurements shown in red.

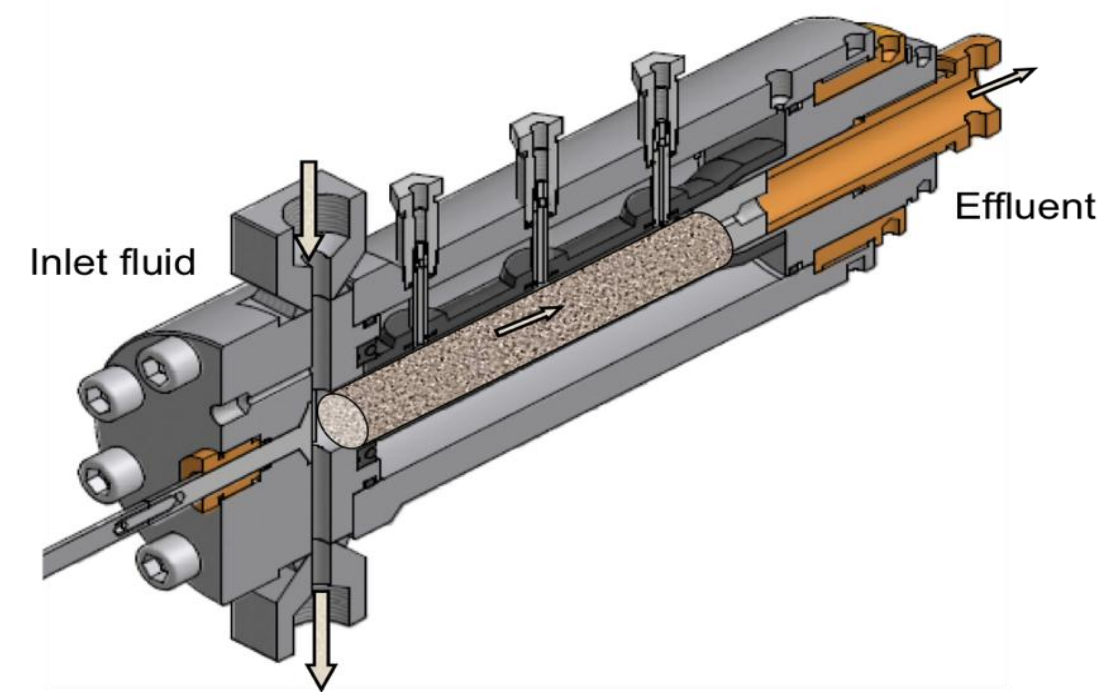

Figure 3.2: Drawing of the fluid-loss cell (courtesy of TEMCO). 

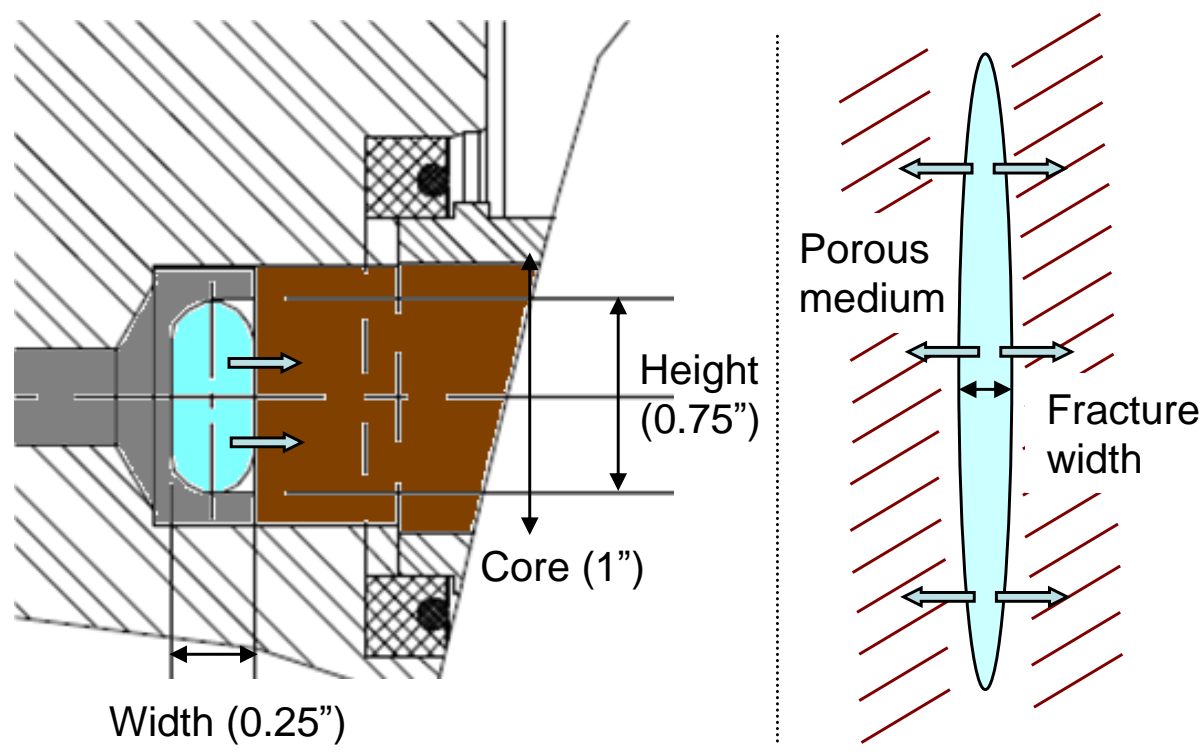

Figure 3.3: Drawing of the fluid-loss cell and the "equivalent" flow pattern in a thin, planar, vertical fracture.

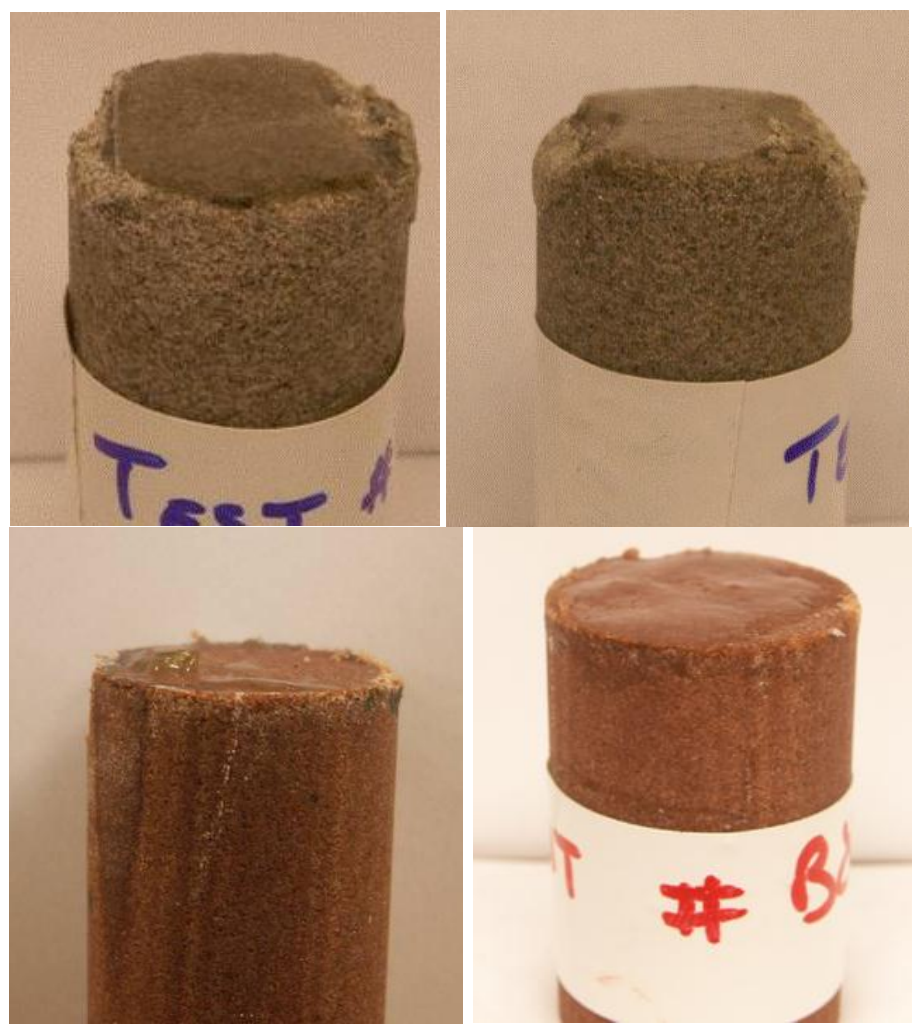

Figure 3.4: External filter-cakes observed after leak-off tests on Berea and Nugget sandstone samples. 


\section{Chapter 4: Results and Discussion for Linear Gels}

About 30 dynamic leak-off experiments have been conducted with linear guar gels. The first goal was to assess the viability of the new experimental setup and laboratory protocols by comparing our data with what has been published in the literature. These experiments also yielded significant results that are worth discussing, either because they provide a new insight or because they confirm previous findings.

\subsection{DynamiC Versus Static Leak-OFF TESTS}

Static leak-off tests have been conducted extensively for about 50 years to assess the fluid-loss properties of drilling muds and fracturing fluids. However, those tests do not mimic the shear conditions experienced by the fluid during field operations. Under dynamic conditions, two competitive forces are acting on the external filter cake. The pressure gradient tends to increase the filter cake thickness whereas the shear rate applied by the circulating fluid tends to dislocate the external filter cake. When analyzing dynamic leak-off tests, one should keep in mind that the thickness and the flow resistance of the filter cake are governed by the quasi-equilibrium between these two competitive effects (Jiao and Sharma 1992; Yi and Peden 1994; Navarrete et al. 1996). Nevertheless, the shear forces do not affect the internal filter cake. This pore-plugging effect gradually reduces the ability of the filtrate to flow, which complicates the analysis of dynamic leakoff data over time.

\subsection{EfFect of Pressure Drop}

As leak-off tests are essentially filtration tests, one can expect higher leak-off rates at larger pressure drops. The pressure drop refers here to the difference between the 
inlet pressure, which is the fluid pressure within the flow-through slot of the core holder, and the outlet pressure which is the fluid pressure at the core outlet, upstream of the BPR. Figure 4.1 shows leak-off rates versus square root of time for $30 \mathrm{lbm} / \mathrm{Mgal}$ guar gels under filtration pressures ranging from 550 to 2000 psi. At early times, the filtration pressure drives the fluid to flow through the core, thereby leading to large initial invasion. As the filtrate accumulates within the core sample, the resistance to flow becomes larger and the leak-off rates significantly decrease.

The wall-building leak-off coefficient is proportional to the slope of the cumulative leak-off volume versus the square root of time after establishment of a competent filter-cake. After 20 minutes, the three curves shown in Figure 4.1 become linear and their slopes are almost parallel from one test to another. Therefore, the three tests yield similar values of leak-off coefficients $(0.0032$ to $0.0034 \mathrm{ft} / \sqrt{\mathrm{min}})$. Although the spurt-loss appears to be highly affected by the filtration pressure, the leak-off coefficient does not seem to be affected by the filtration pressure, at least in our range of pressures (550 to $2000 \mathrm{psi}$ ).

If the flow resistance (product of the permeability with the thickness) of the filter-cake was independent of the applied pressure, the leak-off rate would be proportional to the filtration pressure. However, the three tests exhibit similar leak-off rates, so the flow resistance of the filter-cake varies with the filtration pressure. Therefore, the filter-cake is compressible. Additional tests conducted at 20 and 40 lbm/Mgal polymer concentration yielded very similar results, however those results are not presented here for brevity. 


\subsection{Effect of Core Permeability}

Figures 4.2 and 4.3 show the cumulative leak-off volume and the pressure response of tests conducted at 1000 psi with three core samples: Nugget sandstone (1.5 $\mathrm{mD})$, low-permeability Berea sandstone $(25 \mathrm{mD})$, and high-permeability Berea sandstone (400 mD). The fracturing fluid was a $30 \mathrm{lbm} / \mathrm{Mgal}$ linear gel in all of these cases.

The establishment of a competent filter cake depends on the driving force applied to it. For high permeability cores, the filtration process may not be effective for a long time, thereby yielding large spurt-loss volumes and significant invasion of the gel into the rock matrix. Figure 4.3 indicates that for the high-permeability core sample, the filtration at the core face gradually becomes effective after about an hour. The slow increase in pressure suggests that the external filter-cake is not fully established and does not seal the core face properly. This was confirmed by the presence of some polymers at the core outlet. On the contrary, effective filtration yields a transparent, polymer-free, filtrate collected at the outlet. For the high-permeability core test, the effluent was brown and opaque at early times. This indicates limited filtration at the surface and inside the core sample. For the low-permeability test, the filtration process rapidly becomes effective, as revealed by the pressure profile in Figure 4.3 and the limited invasion at early times in Figure 4.2.

Once a competent filter-cake has been formed, the experiments show different leak-off rates for different core permeabilities. Figure 4.2 exhibits leak-off coefficients of $0.0033,0.0178$ and $0.055-\mathrm{ft} / \sqrt{\mathrm{min}}$ for cores of $1.5,25$ and $400 \mathrm{mD}$, respectively. As a rule of thumb, a change in two orders of magnitude in the rock permeability results in a change of one order of magnitude in the leak-off coefficient. At the pore scale, this may be explained by the extent of the pore plugging and/or polymer bridging at the core face. 
As mentioned previously, the slow increase in pressure shown in Figure 4.3 is undesirable and is due to limitations in the pumping equipment. A loading pump with a higher maximum flow rate would have enabled us to compensate the large fluid losses and would have maintained a constant pressure drop across the core during the entire leak-off test.

\subsection{Effect of Polymer Concentration}

For proper fluid selection, one needs to examine numerous fluid properties, encompassing the fluid ability to carry proppant, the compatibility with the rock formation and the fluid-loss properties. Figures 4.4 and 4.5 show experiments conducted with $400-\mathrm{mD}$ cores at 550-psi differential pressure and with gel concentration ranging from 20 to $40 \mathrm{lbm} / \mathrm{Mgal}$. Figure 4.4 yields leak-off coefficients of $0.051,0.048$ and $0.055-\mathrm{ft} / V_{\mathrm{min}}$ for gel loading of 20,30 , and $40 \mathrm{lbm} / \mathrm{Mgal}$, respectively. It implies that the fully established filter-cake is not very sensitive to the gel loading under these conditions.

The time required to obtain a fully established filter-cake differs in the three experiments. The location of the inflexion points on the sigmoid leak-off volume curves (Figure 4.4) correlates with the decay in permeability (Figure 4.5). Both indicate how the filter-cake behaves over time. In Figure 4.4, higher gel loadings yield larger spurt-losses. This trend is consistent with other experiments conducted with core samples of 1.5 and $25 \mathrm{mD}$. Increasing the gel loading increases the viscosity of the fluid and thus the internal shear force for a given shear rate. As a result, the increased shear force is more effective at dislocating the external filter-cake, and it takes more time to reach the quasiequilibrium state where the shear forces and the pressure gradient applied to the filtercake balance each other. 


\subsection{EFFect OF SHEAR RATE History}

Figure 4.6 shows the influence of the shear rate history on the leak-off rate. The experiment was run with a $30-\mathrm{lbm} / \mathrm{Mgal}$ linear gel exposed to a $1.5-\mathrm{mD}$ core sample subject to a 550-psi differential pressure. From the previous experiments (Figure 4.3), it was shown that the shear forces alter the establishment of the filter-cake. In this experiment, the goal was to evaluate the ability of the shear forces to dislocate an already fully developed filter-cake. The motivation behind this was to see whether the filter-cake dynamically accommodates for changes in shear forces to satisfy the force balance.

The experiment revealed no significant alterations in the leak-off rate. Once established, the filter-cake is not particularly sensitive to the shear rate. This result challenges the idea that the filter-cake resistance to flow follows the shear/filtration force balance. At the pore scale, two factors may be responsible for this behavior: (1) the competent external filter-cake is dense and compressible enough to be insensitive to the shearing forces; (2) a significant flow resistance comes from internal pore plugging, which is independent of the shear forces acting on the core face. The two factors may combine to some extent, thereby increasing the level of complexity of the analysis.

\subsection{Comparison With Published Data}

The leak-off of a linear gel can depend on a multitude of parameters: core permeability, filtration pressure, imposed shear rate, fluid type, temperature, polymer loading, etc. This makes a direct comparison with the wealth of data in the public domain cumbersome. We compare here our leak-off data with the work published by McGowen and Vitthal (1996) and the work of Elbel, Navarrete and Poe (1995). The leak-off data and testing conditions are specified in Table 3.1. 
The first leak-off coefficient $(0.0032-\mathrm{ft} / \sqrt{ } \mathrm{min})$ is taken from Equation 5, page 6 of McGowen and Vitthal (1996), for Ohio sandstones having permeabilities ranging from 0.3 to $1 \mathrm{mD}$. It matches our leak-off data for Nugget sandstones having a permeability of $1.5 \mathrm{mD}$. The second leak-off coefficient $(0.027-\mathrm{ft} / \sqrt{\mathrm{min}})$ is estimated from Figure 21 , in McGowen and Vitthal (1996), for a 12-mD Texas Cream limestone sample. The last data point $(0.038-\mathrm{ft} / \sqrt{\mathrm{min}})$ is taken from Table 2, in Elbel, Navarrete and Poe (1995) for a high-permeability core $(175 \mathrm{mD})$. These data are consistent with our leak-off data for permeabilities ranging from $1 \mathrm{mD}$ to $390 \mathrm{mD}$. The comparisons support that the observation that the leak-off coefficient varies with the square root of the rock permeability. However, the fluid used in these papers (linear HPG) differs from the linear guar gel formulation we used. Our leak-off data for linear guar fluids agreed well with similar guar leak-off tests conducted by commercial laboratories. These data are not in the public domain and cannot be presented in this study. We believe that the comparisons made validate our apparatus and laboratory protocols for measuring dynamic leak-off over time. 


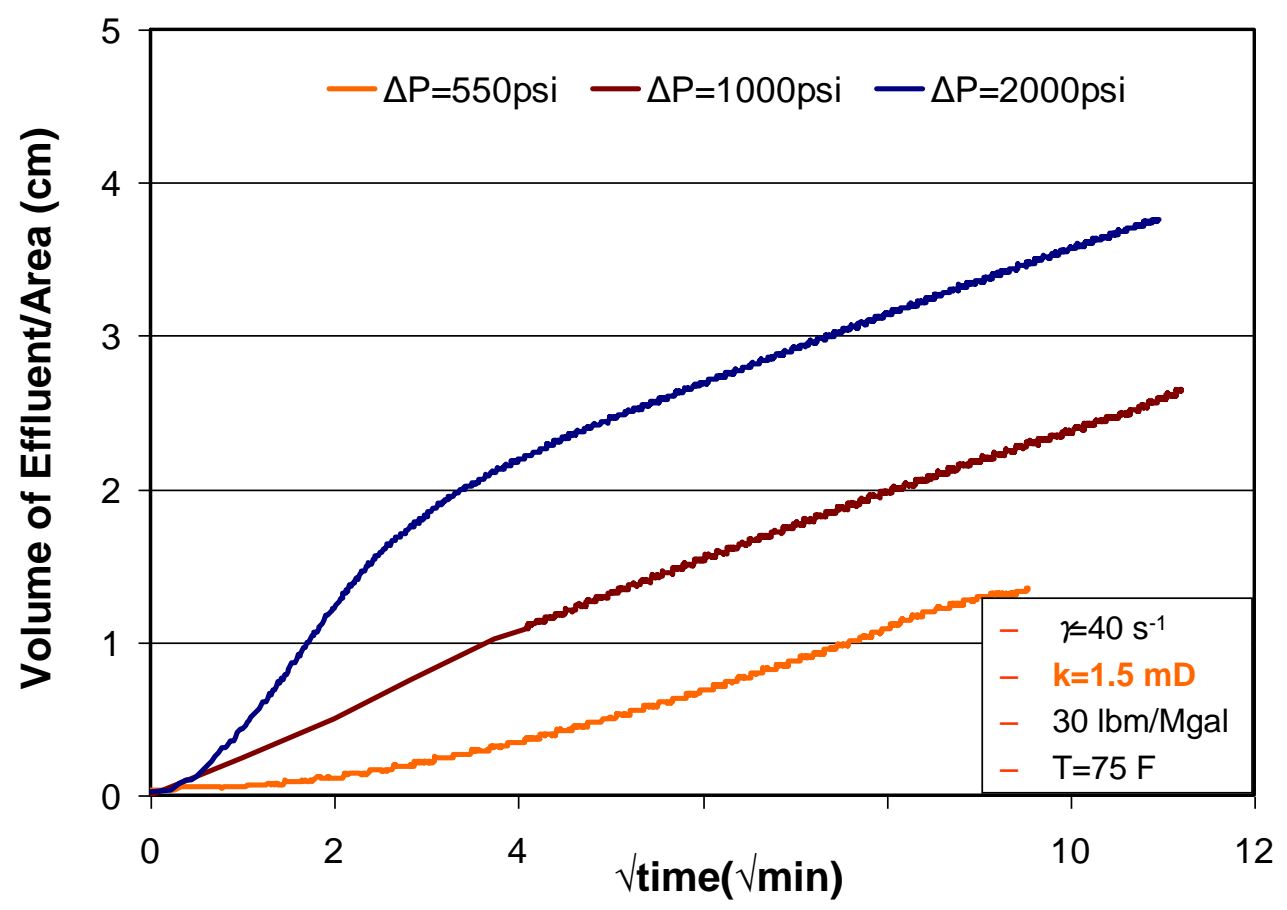

Figure 4.1: Effect of pressure drop on 1.5-mD cores.

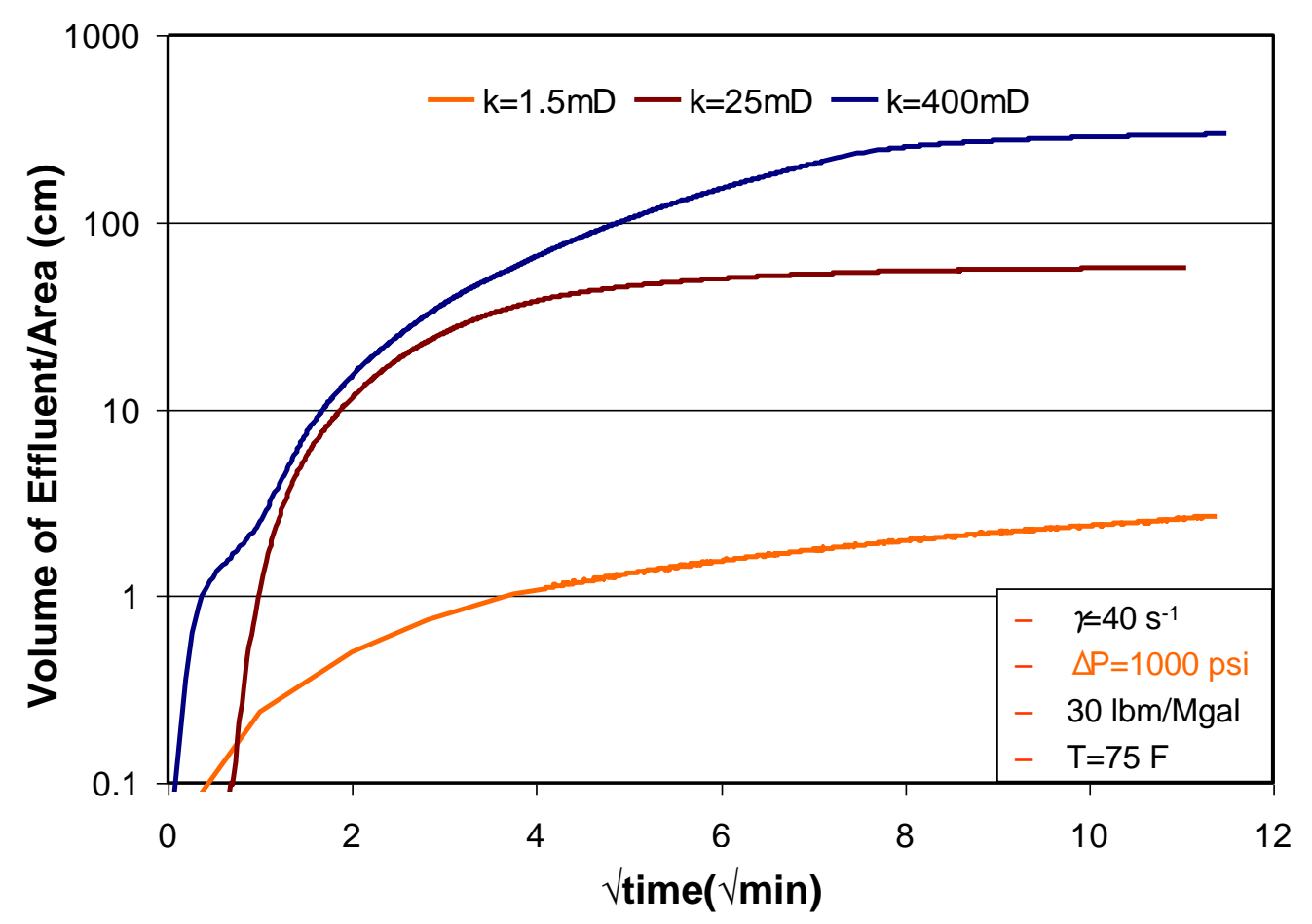

Figure 4.2: Effect of rock permeability at $\Delta \mathrm{P}=1000 \mathrm{psi}$ (effluent volume). 


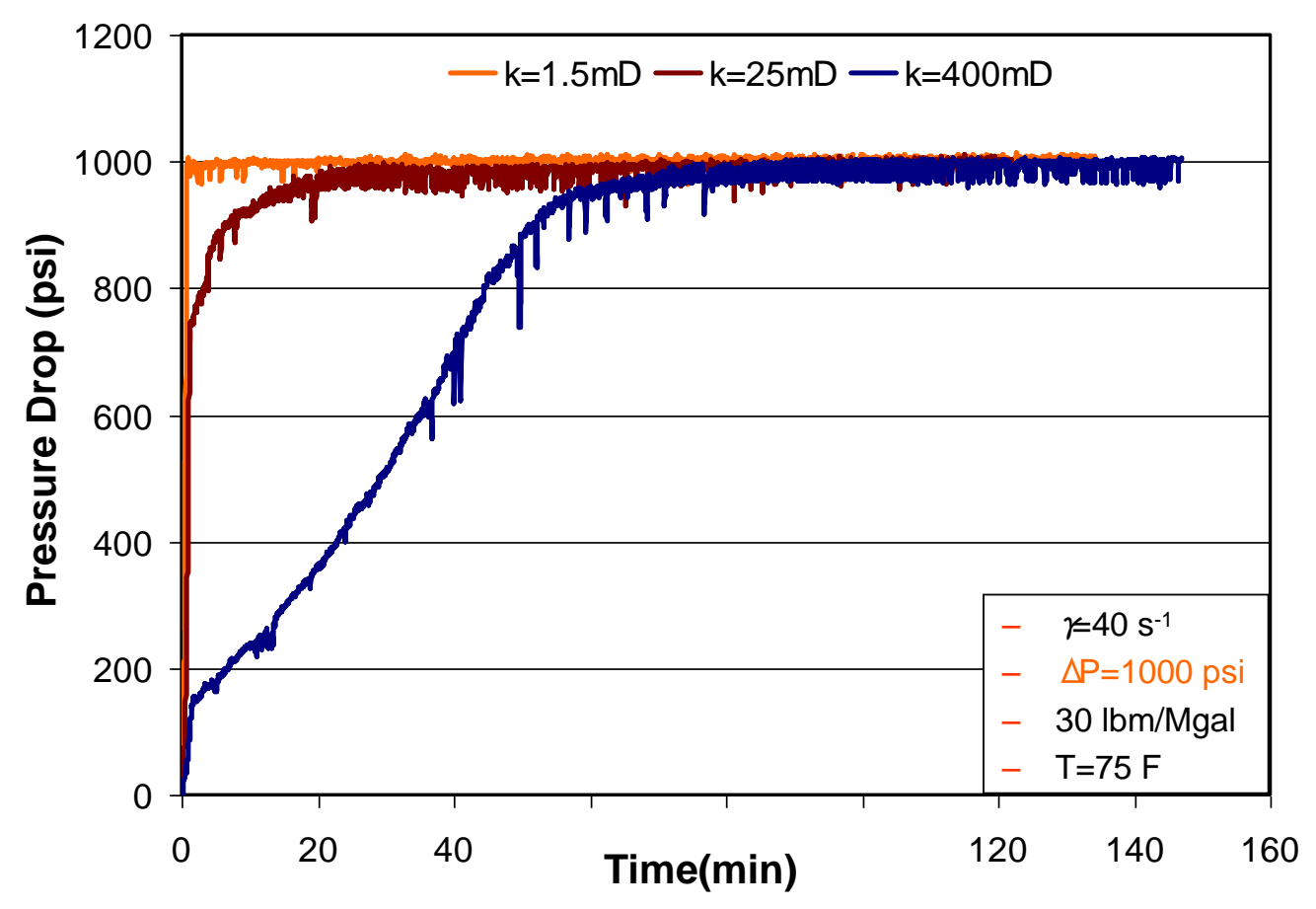

Figure 4.3: Effect of rock permeability at $\Delta \mathrm{P}=1000$ psi (pressure profile).

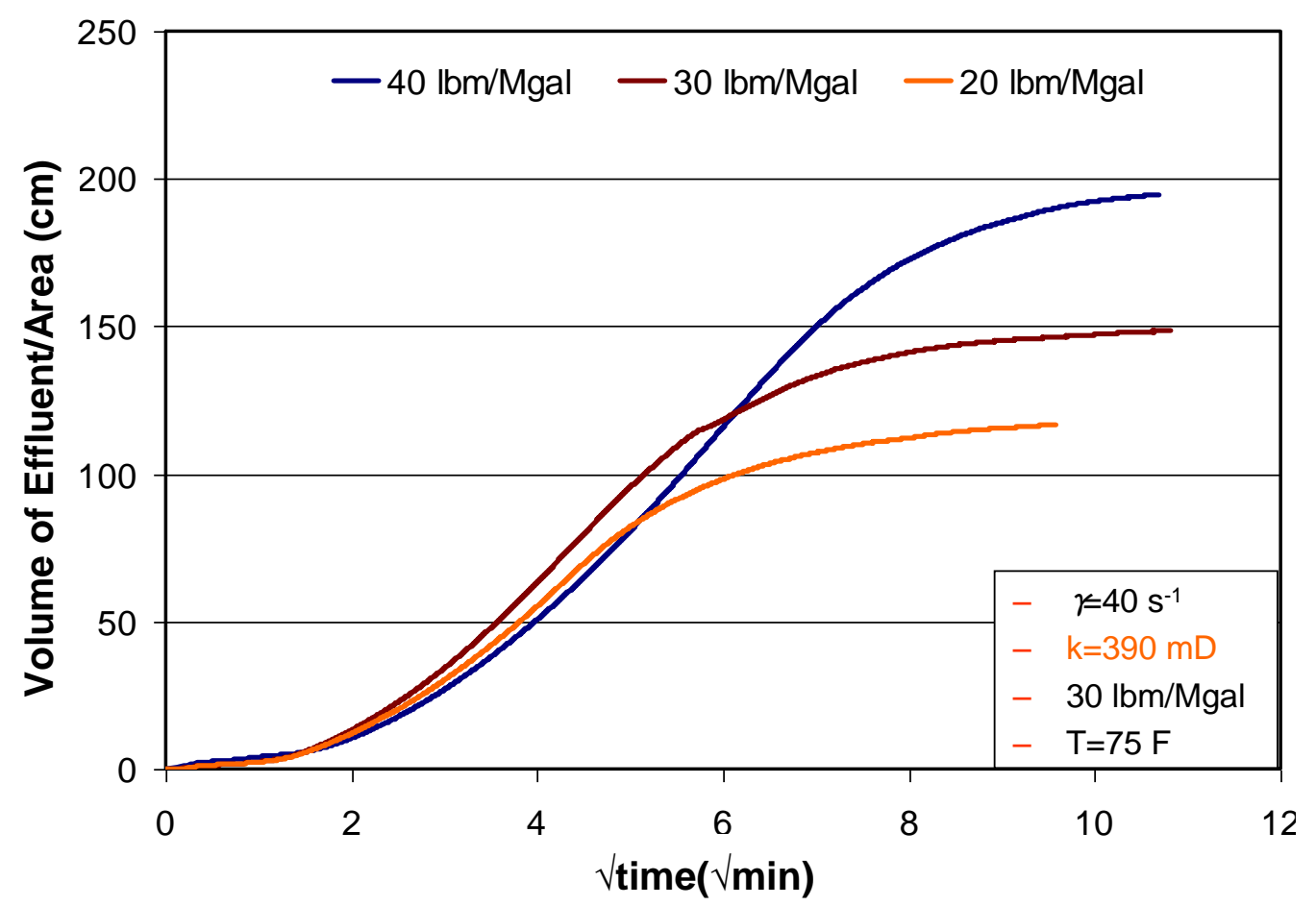

Figure 4.4: Effect of gel loading on 390-mD (effluent volume). 


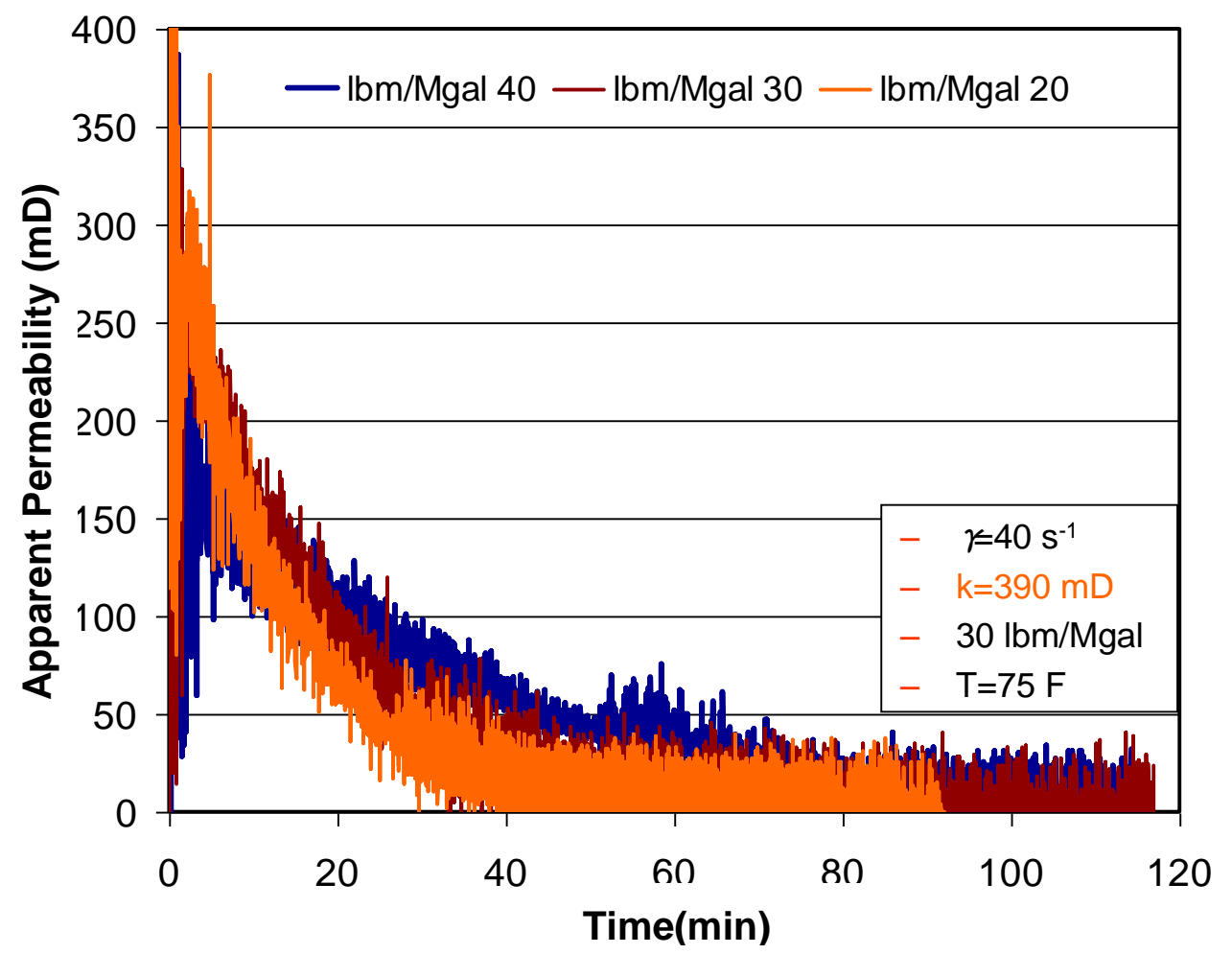

Figure 4.5: Effect of gel loading on 390-mD (permeability profile).

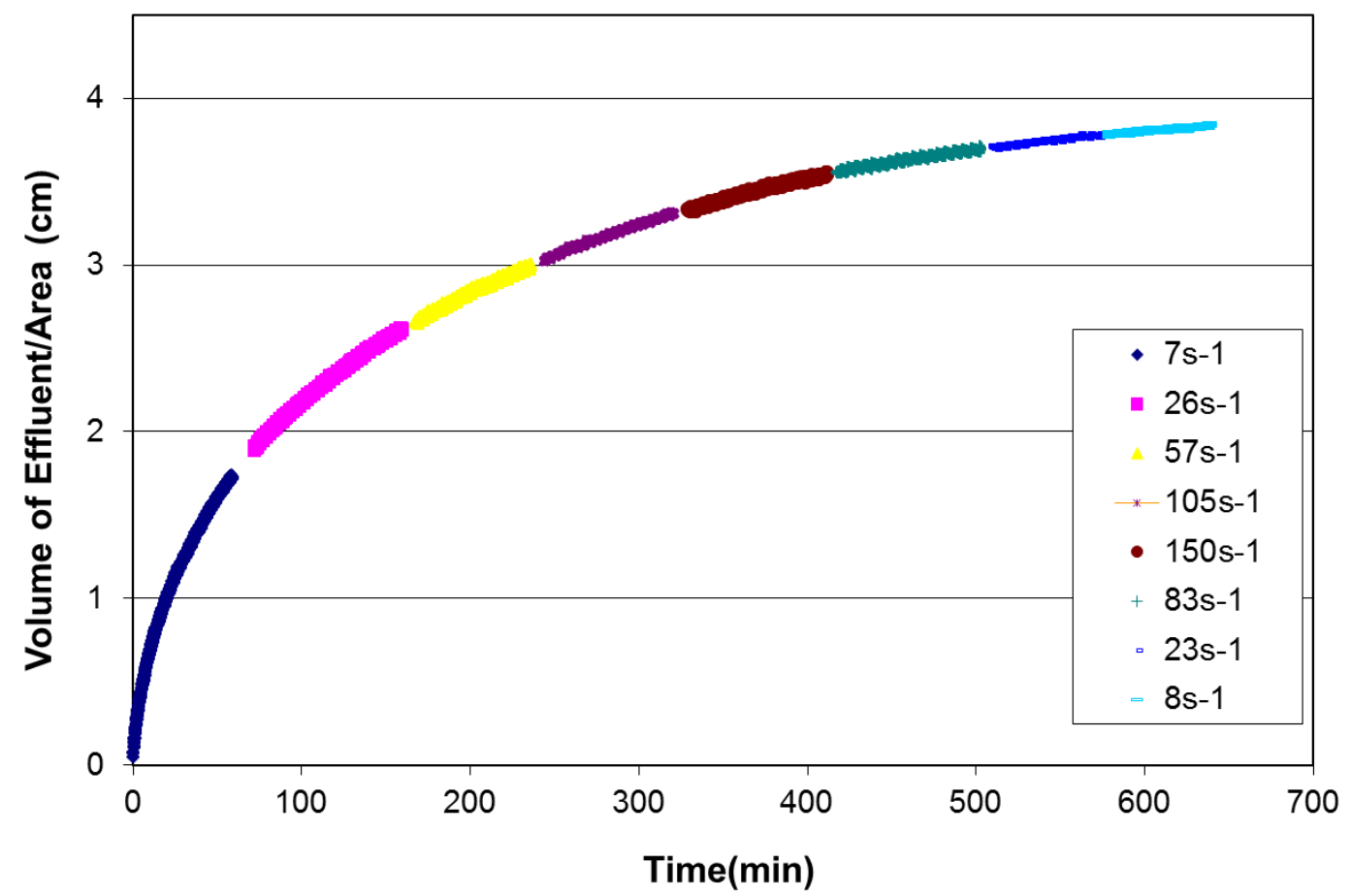

Figure 4.6: Effect of shear rate history. 


\section{Chapter 5: Results and Discussion for Nitrogen Foams}

Several papers (Harris 1985, 1987) and field observations (Grundman 1983) have acknowledged the superior fluid-loss properties of foams. However, very limited qualitative results have supported this claim. In the field, this lack of data has contributed to occasional screenouts. Proper fracture design requires the knowledge of the fluid-loss properties of the fluid in order to decide whether foam fracturing is more suitable than traditional fracturing. Multi-phase leak-off coefficients may be used with a compositional fracturing simulator to evaluate the fracture geometry, and the return permeability results may be incorporated in a productivity index model to assess the potential increase in production.

This report focuses on the impact of the pressure drop, rock permeability, and foam quality on the multi-phase leak-off of nitrogen foams. Other parameters are nonetheless likely to affect the foam leak-off, such as polymer loading, fluid shear rate, and reservoir pressure. For the experiments presented here, the polymer loading was always $30 \mathrm{lbm} / \mathrm{Mgal}$; the foam shear rate was always around $20 \mathrm{~s}^{-1}$ at the inlet.

\subsection{FOAM RHEOLOGY}

For each leak-off test, we monitored the pressure drop within the foam loop over time. These measurements, conducted at constant shear rate, are presented in Figure 5.1. As seen in Figure 5.1, some pressure oscillations occur in the first ten minutes. These oscillations are due to the sudden expansion of the foam caused by the opening of the valve located at the inlet of the core holder at the reference time $\mathrm{t}=0$. This perturbation generates some initial instability but the oscillations disappear as the foam stabilizes. Later, the pressure drop remains constant as the foam is flowing at constant shear rate. 
This is a clear indication that the foam characteristics remain stable throughout the leakoff experiments. The stabilized pressure drop (and therefore the foam viscosity) increases as the foam quality increases from one test to another.

Figure 5.2 shows some rheology data for $\mathrm{N}_{2}$ foams with quality ranging from 0 to 0.7. The base gel was $30 \mathrm{lbm} / \mathrm{Mgal}$ linear guar; the temperature was $80^{\circ} \mathrm{F}$; the loop pressure was set at $1000 \mathrm{psi}$; and the shear rate was imposed by the circulating pump. We measured the flow rate and the pressure drop occurring along a segment of the foam loop and we converted these measurements into apparent viscosity versus shear rate, as shown in Figure 5.2. Our measurements support the fact that guar- $\mathrm{N}_{2}$ foams are shearthinning, as the apparent viscosity decreases when the shear rate increases (regardless of the foam quality). At every shear rate, the foam viscosity increases as the quality increases. The increase in viscosity is more dramatic as the quality goes from 0.48 to 0.6. This observation is in good agreement with the widely known fact that the foam viscosity surges once the interactions between gas bubbles become dominant and cause a large energy dissipation. This surge typically occurs at a quality of about 0.5 as shown first by Reidenbach et al. (1986).

Our viscosity measurements are compared to the published data taken from the pioneering work of Reidenbach et al. (1986), and Khade and Shah (2004), which constitute references widely accepted by the industry. Figure 5.3 shows the apparent viscosity measured at a stabilized shear rate of $100 \mathrm{~s}^{-1}$ for $30 \mathrm{lbm} / \mathrm{Mgal}$ guar- $\mathrm{N}_{2}$ foams of different qualities. The first set of data is taken from Table 1 of Reidenbach et al. (1986). The correlations presented in Table 2.1 were obtained with HPG- $\mathrm{N}_{2}$ foam circulated in a foam loop at ambient temperature and at a pressure of 1000 psi. Based on these correlations, $30 \mathrm{lbm} / \mathrm{Mgal} \mathrm{HPG}-\mathrm{N}_{2}$ foam is characterized as follows: $\mathrm{n}=0.4788, \mathrm{C}_{1}=1.32$, 
and $\mathrm{K}_{\mathrm{f}}=0.0065$. The apparent viscosity was then calculated from the equation presented in Table 1 in Reidenbach et al. (1986). The second set of data comes from Table 2 in Khade and Shah (2004). The rheology data correspond to $30 \mathrm{lbm} / \mathrm{Mgal}$ guar- $\mathrm{N}_{2}$ foam circulating in a loop set at a temperature of $100 \mathrm{~F}$ and a pressure of $1000 \mathrm{psi}$. The apparent viscosity at $100 \mathrm{~s}^{-1}$ was calculated from the values of $\mathrm{n}$ and $\mathrm{k}$ provided in this table. As shown in Figure 5.3, our rheology data are consistent with other published data. We have made similar comparisons under various conditions and our rheology data agreed with the published data. This validates our apparatus and laboratory protocols for foam generation and circulation.

\subsection{EfFect OF Pressure Drop}

The foam fluid-loss behavior has been investigated on cores of 1.5, 55 and 390 $\mathrm{mD}$ under pressures varying from 400 to 1500 psi. Figure 5.4 shows the leak-off volume of both liquid and gas for a 0.55 -quality foam exposed to a $1.5-\mathrm{mD}$ core. As with linear gels (Figure 4.1), the filtration pressure significantly affects the initial spurt-loss for both phases. Initially, the driving force applied by the pressure gradient forces the mixture to flow through the core. At later times, the filtration pressure also affects the leak-off coefficient for both phases. This behavior differs from the one exhibited by linear gels. It may be explained by the highly compressible nature of the mixture, which experiences a significant volume expansion as the pressure decreases. At the pore scale, the expanding gas bubbles may push the water out, thus triggering the liquid leak-off as well. Similar fluid-loss behavior has been observed in experiments conducted on 55-mD cores.

Figure 5.5 shows the leak-off rates of foams exposed to $390-\mathrm{mD}$ Berea cores. Under these conditions, the driving force is sufficient to allow the foam mixture to flow as a whole. The foam invades the rock as it can overcome the lower capillary forces 
exerted by larger pore throats. This behavior differs from the leakoff observed through lower permeability cores $(1.5$ and $55 \mathrm{mD})$. For lower permeability rocks and for sufficiently high filtration pressures, the foam can separate into liquid and gas phases. Moreover, Figure 5.5 shows that an increase in the filtration pressure increases the spurtloss but does not significantly affect the leak-off coefficient under these testing conditions. The lowest filtration pressure (465 psi) was already high enough to flow the foam through the core as a whole. We can suppose that there is a threshold pressure above which increasing the filtration pressure does not increase the leak-off rate anymore. Additional testing is required to investigate this behavior at high permeability.

\subsection{EfFect OF Rock Permeability}

Data were generated with 0.6-quality foams to evaluate the impact of the rock permeability on the fluid-loss behavior. Figure 5.6 show the data collected under a 500psi pressure drop. Similar experiments, which have been performed at 1000 and 1450 psi, yielded very similar results. As pointed out in the previous section, foam was observed at the core outlet with the high-permeability cores. Consequently, both the spurt-loss and the leak-off coefficient are significantly larger at $400 \mathrm{mD}$ than at lower permeabilities.

Aside from this particular behavior, the results compare well with the observations made with linear gels as the spurt-loss and the leak-coefficient of both phases are significantly affected by the rock permeability. Indeed, smaller pore throats exert higher capillary forces, thereby reducing the ability of both fluid phases to flow. This reduction in fluid leakoff is not primarily a result of the flow resistance offered by the rock; rather it is a result of the formation of an effective filter cake on the surface of the rock. If the capillary pressure required to force the gas bubbles into the pores is larger 
than the filtration pressure, the leakoff of the gas phase is impeded. This drastically reduces the invasion of the water phase for stable foams. Gas expansion inside the core can also impede the flow of water drastically. The gas expansion effect was more significant in our experiments, compared to the field, since no back pressure was applied.

\subsection{EFFeCT OF FoAm QUALITY}

The effect of foam quality is of particular interest to us since the fluid composition is usually the only parameter the stimulation engineer can modify. Figure 5.7 shows both the liquid and gas leak-off of several $\mathrm{N}_{2}$ foams flowing through $55-\mathrm{mD}$ cores under a 500-psi differential pressure. Figure 5.8 shows the liquid and gas leak-off of $\mathrm{N}_{2}$ foams exposed to $1.5-\mathrm{mD}$ cores under a 1000-psi differential pressure.

Under all conditions, foams present superior fluid-loss control properties than linear gels, regardless of the foam quality. A comparison between Figures 4.2 and 5.6 reveals a reduction in the liquid fluid-loss by an order of magnitude at a permeability of $55 \mathrm{mD}$. This reduction is less dramatic but remains significant at lower permeability (1.5 $\mathrm{mD}$ ), as illustrated in Figure 5.8. The comparison between foams of different qualities show that the liquid leak-off decreases as the foam quality increases. This observation is quite intuitive, as less liquid is used at higher foam quality. Additionally, the invasion of gas into the porous medium reduces the invasion of liquid because of relative permeability effects.

Figures 5.4 to 5.11 show the ability of the free gas phase to leak-off under our fracturing conditions. To the best of our knowledge, this report presents the first quantitative study of dynamic gas leak-off over time. It establishes the ability of the gas bubbles to break from the foam structure and to flow through the porous medium by a 
mechanism other that solubility. Figures 5.7 and 5.8 seem to indicate that the gas leakoff increases as the foam quality increases, at least in the lower range of foam qualities. At qualities higher than about $60 \%$, the gas leak-off does not seem to increase anymore, and it can even decrease, as shown in Figures 5.7 and 5.8. This observation might be explained by the fundamental change occurring within the fluid at the microscopic scale. At qualities above $50 \%$ or so, the interactions between gas bubbles become preponderant, thereby increasing the internal friction and the viscosity of the foam. There is nonetheless some scatter in the data at qualities above $60 \%$. For instance, Figure 5.8 shows a surprisingly large gap between the gas leak-off of foams at qualities of $62 \%$ and $68 \%$. In view of the discrepancies noticed in our data, we believe that it is too premature to conclude that the gas leak-off decreases with increasing inlet quality at high qualities. Additional tests at higher qualities (above 60\%) and at high back pressures are needed to further investigate this behavior.

Figures 5.9 and 5.10 show the leak-off coefficients for liquid and gas phases under various testing conditions. These figures clearly show the effect of the foam quality on multi-phase leak-off. The data seem to follow some general trends. This is encouraging when deriving empirical correlations for both the liquid and the gas leak-off coefficients. It is nonetheless premature to extent the general trends to lower rock permeabilities or lower pressure drop. A systematic comparison between the bubble size distribution and the pore size distribution would benefit our understanding of the physics of the multi-phase filtration process.

\subsection{COMparison With Published Data}

We compared our $\mathrm{N}_{2}$ foam leak-off data with the data published by Harris (1985) and by Penny, Conway and Lee (1985). These papers are the only known references on 
foam leak-off. The leak-off data measured by Harris $(1985,1987)$ were obtained with a semi-static apparatus which is not representative of the flow experienced in a fracture. The data from Penny, Conway and Lee (1985) were obtained with a static apparatus. This is a significant difference since our study reports truly dynamic leak-off data. Also, the base-fluid was a linear HPG fluid which is different from the linear guar formulation we used. Despite these limitations, we compared these results to see whether our findings were consistent. The dynamic leak-off coefficients we are reporting here are typically lower than the values reported previously. They are nonetheless of the same order of magnitude.

The leak-off data are included in Table 5.1 which contains four sections: (1) the total (liquid+gas) leak-off coefficient of guar- $\mathrm{N}_{2}$ foams reported in this paper, (2) the leak-off coefficient of linear gels reported in this paper, (3) the total leak-off coefficient of HPG-N $\mathrm{N}_{2}$ foams reported by Harris (1985), and (4) the total leak-off coefficient of HPG-N ${ }_{2}$ foams reported by Penny, Conway and Lee (1985). As mentioned earlier, a direct comparison with public data is cumbersome. There is very little published data for foam leak-off and there are a multitude of parameters. The first set of data is taken from Table 1 in Harris (1985). The second set of data is taken from Figure 10 in Penny, Conway and Lee (1985). The experimental conditions are reported in Table 5.1 of this report.

More significantly, we can directly compare the linear and foam leak-off data under similar experimental conditions. The use of foams greatly improves the fluid-loss control properties as compared to linear gels. The total foam leak-off coefficient is significantly lower than the gel leak-off. This is particularly true in high permeability formations: $0.0163 \mathrm{ft} / \sqrt{ }_{\min }$ versus $0.055 \mathrm{ft} / V_{\min }$ for $390-\mathrm{md}$ cores, and $0.0048 \mathrm{ft} / \sqrt{\mathrm{min}}_{\mathrm{m}}$ 
versus $0.0167 \mathrm{ft} / \sqrt{\mathrm{min}}$ for $55-\mathrm{md}$ and $25-\mathrm{mD}$ cores respectively. At lower permeability ( 1 $\mathrm{mD}$ ), the reduction in the leak-off coefficient is not as significant: 0.0013 and 0.0041 $\mathrm{ft} / \sqrt{\min }$ for the foams versus 0.0032 and $0.0033 \mathrm{ft} / \sqrt{\min }$ for the linear gels. However, the spurt-loss was significantly lower in all the cases. The ability of the foam to form a rapid wall-building filter-cake is critical in reducing the fluid-loss. The leak-off coefficient data do not captured this transient behavior, and one may also refer to spurt-loss data when evaluating the fluid-loss properties of a fluid. Under all the testing conditions reported here, energizing the fracturing fluid has reduced the total amount of fluid lost into the formation. 
Table 5.1: Comparison of foam leak-off data with published data.

\begin{tabular}{|c|c|c|c|c|c|}
\hline \multicolumn{3}{|c|}{$\begin{array}{c}\mathbf{N}_{2} \text {-guar (this study) } \\
\Gamma=0.6, \mathrm{~T}=80 \mathrm{~F}, \gamma=20 \mathrm{~s}^{-1} \text {, loading }=301 \mathrm{~lm} / \mathrm{Mgal}\end{array}$} & \multicolumn{3}{|c|}{$\begin{array}{c}\text { Linear guar (this study) } \\
\mathrm{T}=80 \mathrm{~F}, \gamma=40 \mathrm{~s}^{-1}, \text { loading }=30 \mathrm{lbm} / \mathrm{Mgal}\end{array}$} \\
\hline k (mD) & $\Delta \mathbf{P}(\mathbf{p s i})$ & $\mathbf{C}_{\text {wtotal }}(\mathbf{f t} / \sqrt{\text { min }})$ & $\mathrm{k}(\mathrm{mD})$ & $\Delta \mathbf{P}(\mathrm{psi})$ & $\mathrm{C}_{\mathrm{wtotal}}(\mathrm{ft} / \sqrt{ } \min )$ \\
\hline 1.5 & 450 & 0.0013 & 1.5 & 550 & 0.0032 \\
\hline 1.5 & 950 & 0.0041 & 1.5 & 1000 & 0.0033 \\
\hline 55 & 500 & 0.0048 & 25 & 500 & 0.0167 \\
\hline 55 & 950 & 0.0053 & 25 & 1000 & 0.0178 \\
\hline 390 & 465 & 0.0089 & 390 & 550 & 0.051 \\
\hline 390 & 800 & 0.0163 & 390 & 1000 & 0.055 \\
\hline \multicolumn{3}{|c|}{$\mathrm{N}_{2}$-HPG (Harris, 1985) } & \multicolumn{3}{|c|}{$\mathrm{N}_{2}$-HPG (Penny et al., 1985) } \\
\hline $\mathrm{k}(\mathrm{mD})$ & $\Delta \mathbf{P}(\mathbf{p s i})$ & $\mathbf{C}_{\text {wtotal }}(\mathbf{f t} / \sqrt{\min })$ & $\mathrm{k}(\mathrm{mD})$ & $\Delta \mathbf{P}(\mathrm{psi})$ & $\mathbf{C}_{\mathrm{wtotal}}(\mathbf{f t} / \sqrt{\min })$ \\
\hline 0.3 & 500 & 0.00069 & 0.1 & 1000 & 0.0008 \\
\hline 0.3 & 1000 & 0.00134 & 1 & 1000 & 0.0025 \\
\hline 13 & 1000 & 0.0112 & 10 & 1000 & 0.0078 \\
\hline 18.6 & 500 & 0.0108 & 55 & 1000 & 0.018 \\
\hline 17 & 200 & 0.0097 & 100 & 1000 & 0.029 \\
\hline 137 & 200 & 0.0265 & 390 & 1000 & 0.048 \\
\hline
\end{tabular}

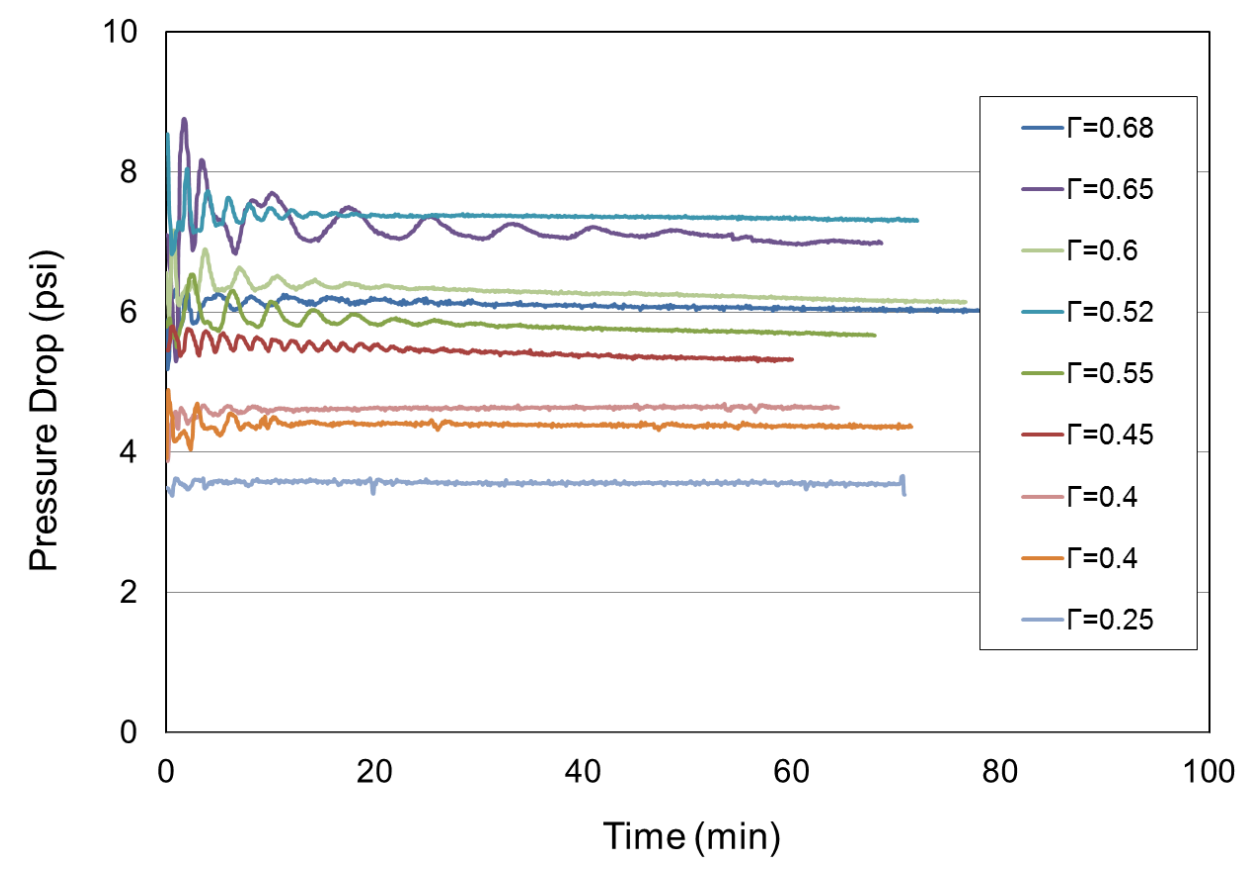

Figure 5.1: Pressure drop measured in the foam loop over time. 


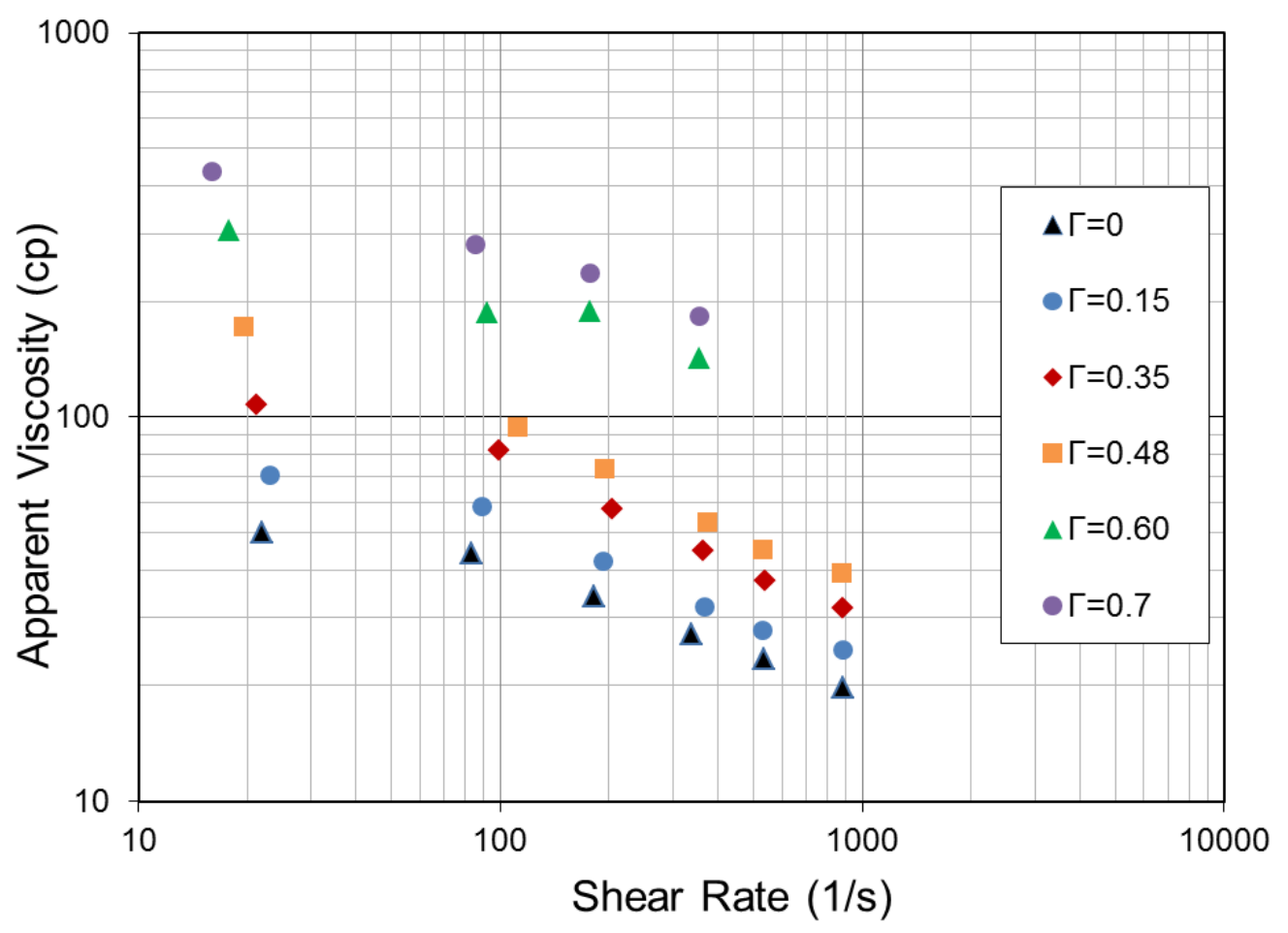

Figure 5.2: Foam viscosity versus shear rate for multiple foam qualities.

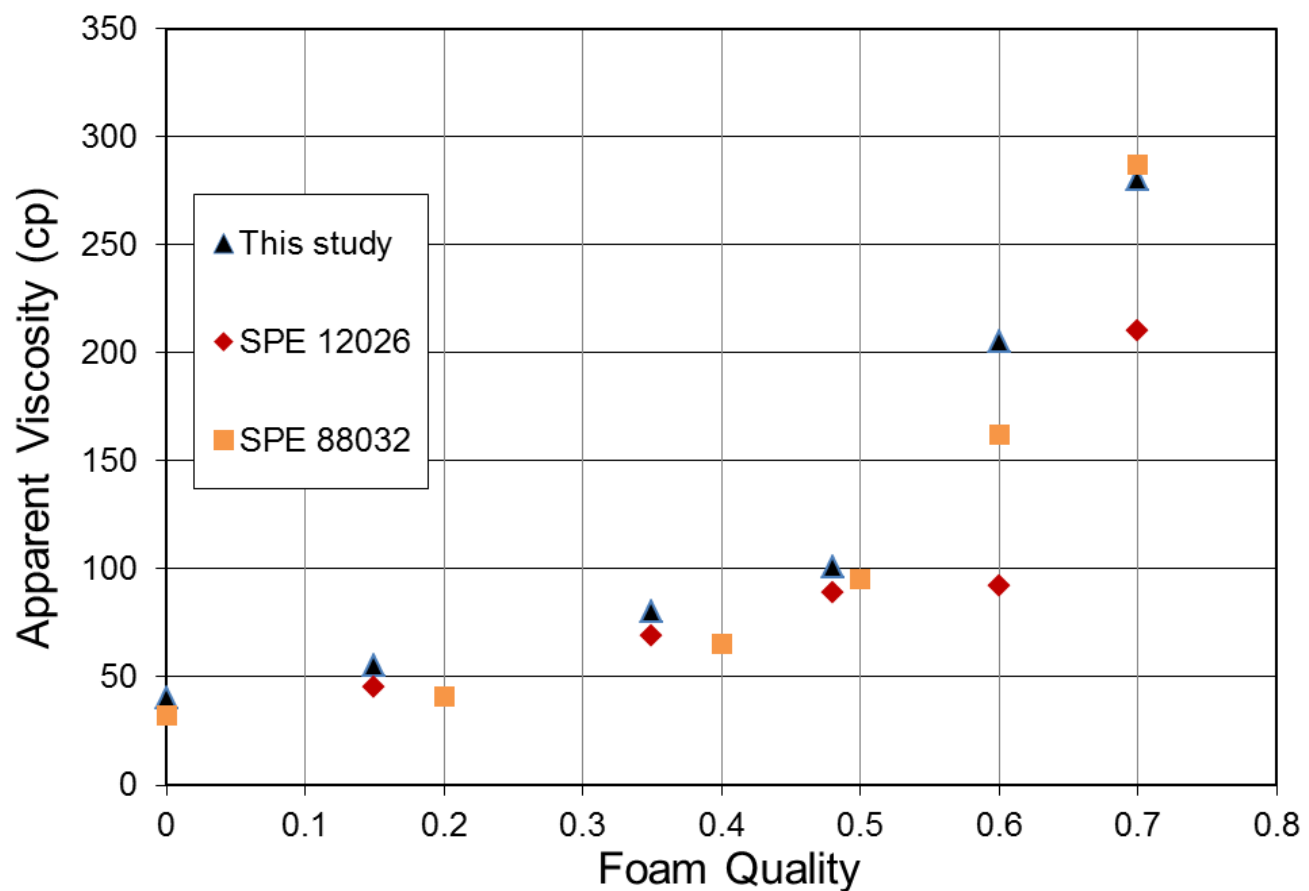

Figure 5.3: Comparison of foam viscosity measurements at a shear rate of $100 \mathrm{~s}^{-}{ }^{1}$. 


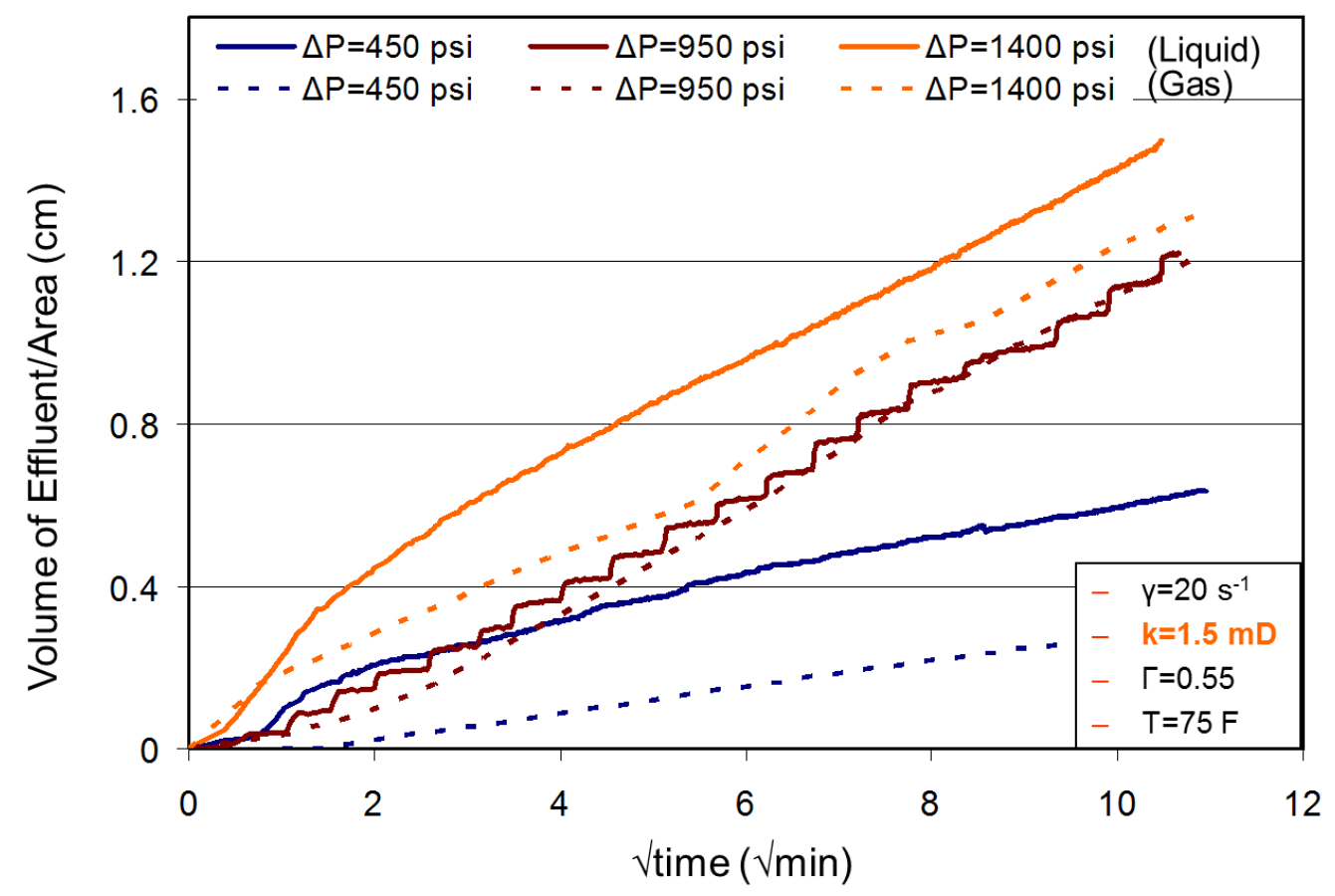

Figure 5.4: Effect of pressure drop on liquid and gas effluents for 1.5-mD cores.

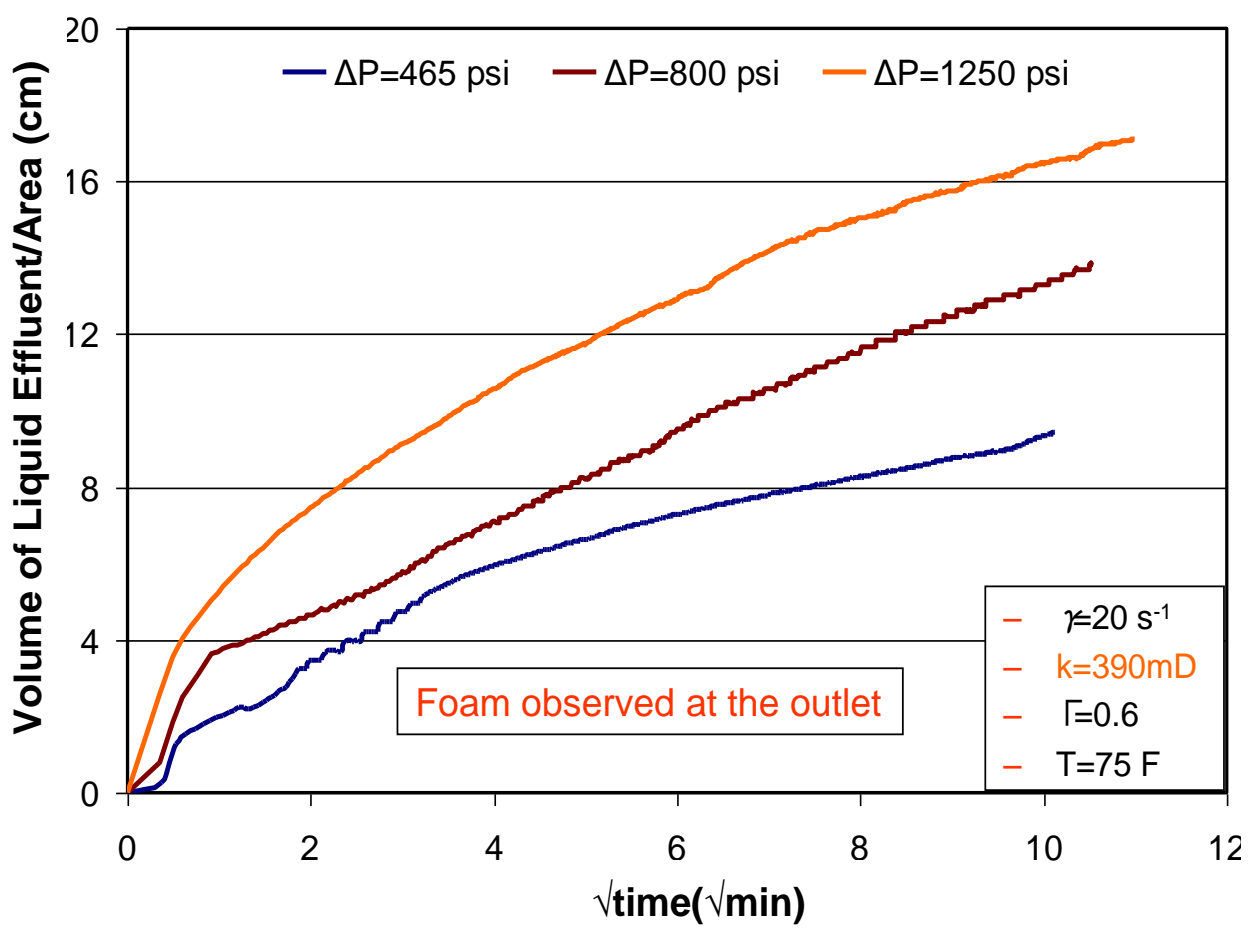

Figure 5.5: Effect of pressure drop on foam effluent for 390-mD cores. 


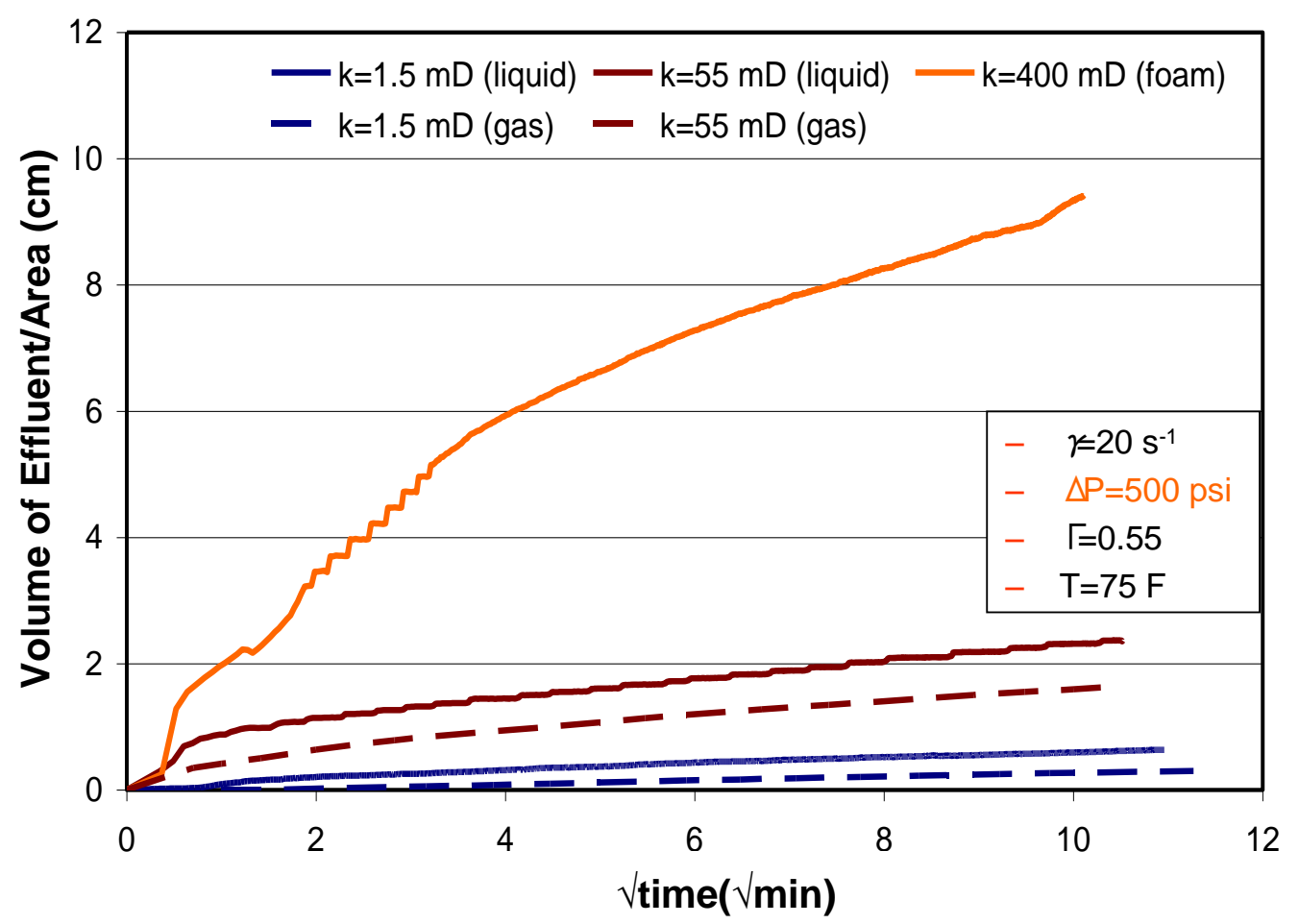

Figure 5.6: Effect of rock permeability on fluid effluents for cores exposed at 500 psi.

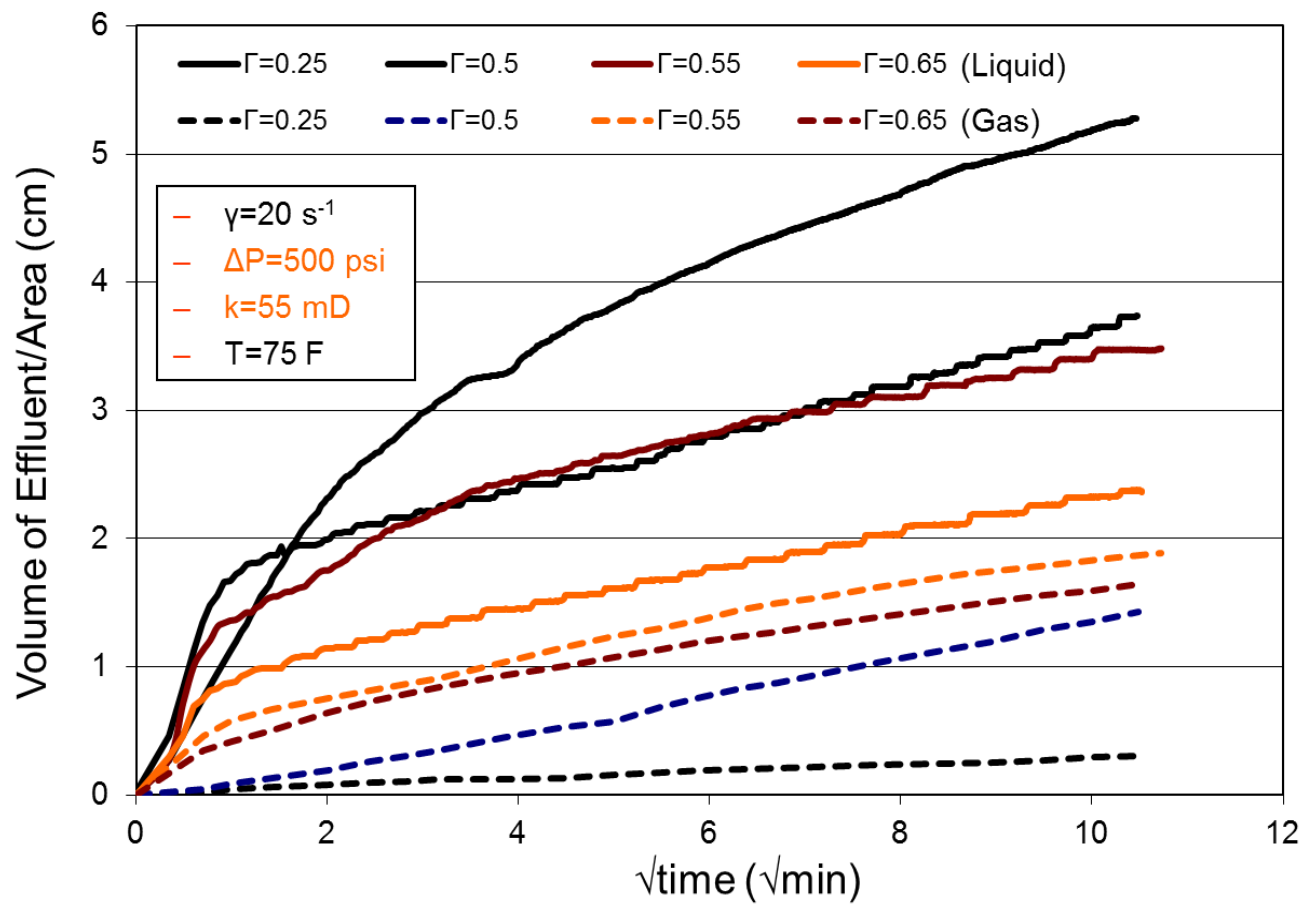

Figure 5.7: Effect of foam quality on liquid/gas leak-off for 55-mD cores under a 500-psi pressure drop. 


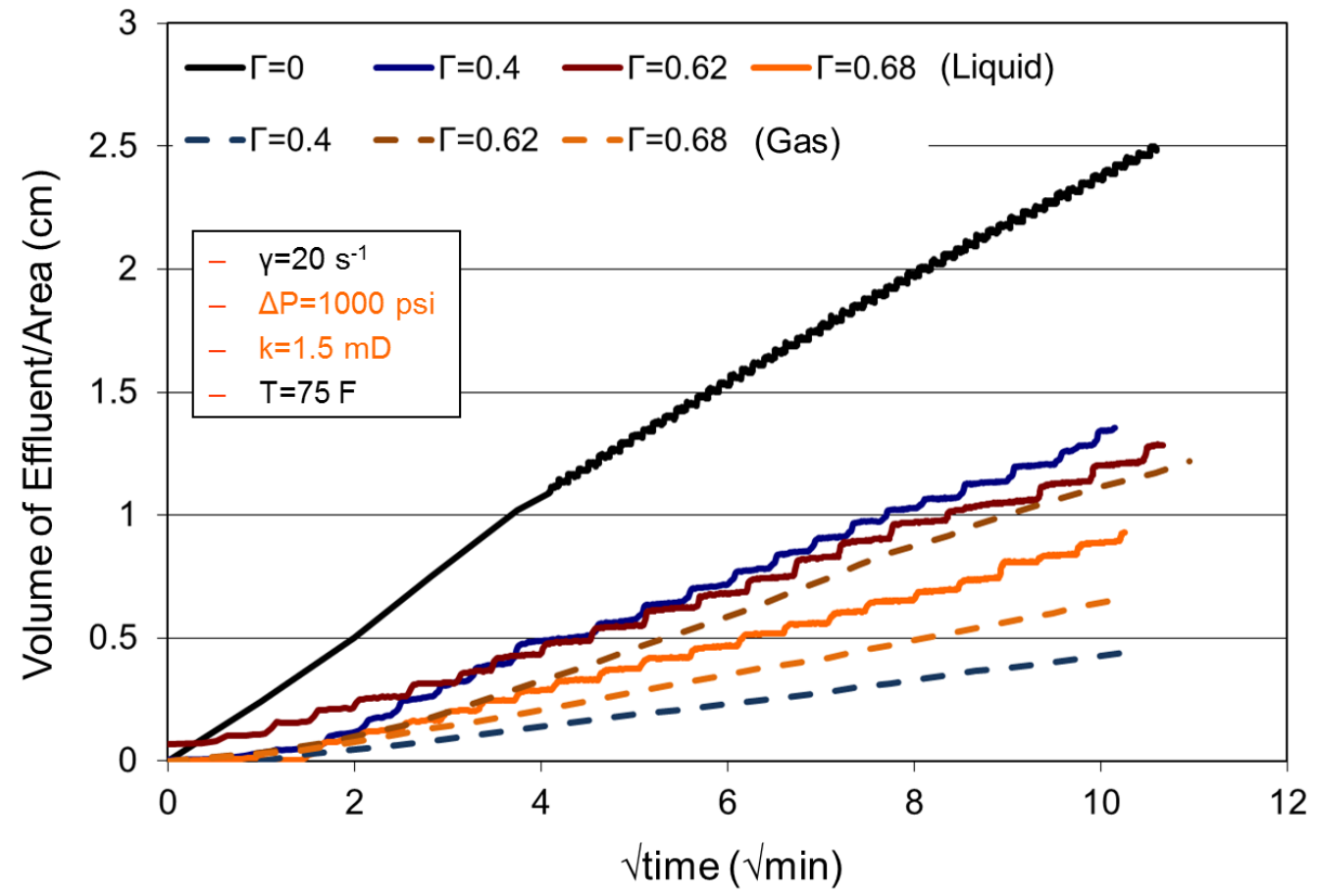

Figure 5.8: Effect of foam quality on liquid/gas leak-off for 1.5-mD cores under a 1000psi pressure drop.

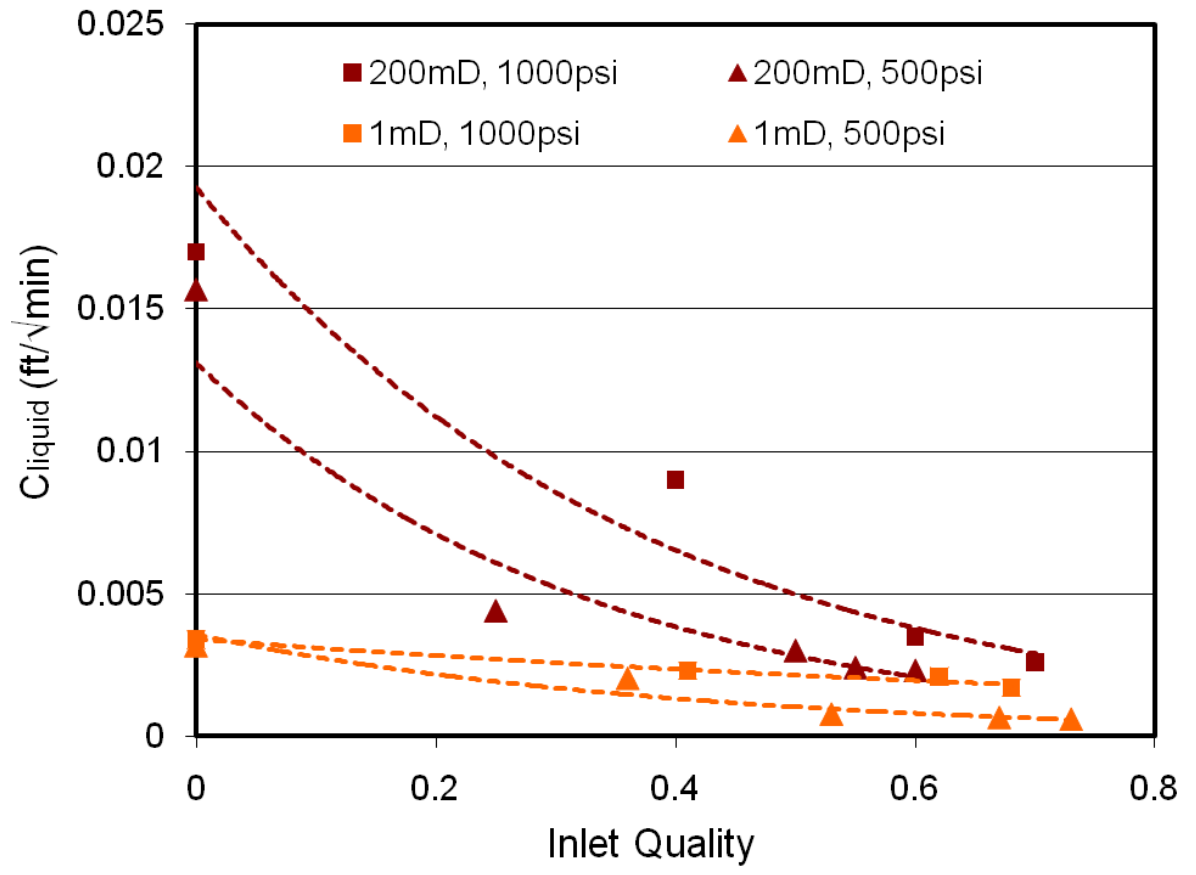

Figure 5.9: Effect of foam quality on the liquid leak-off coefficient. 


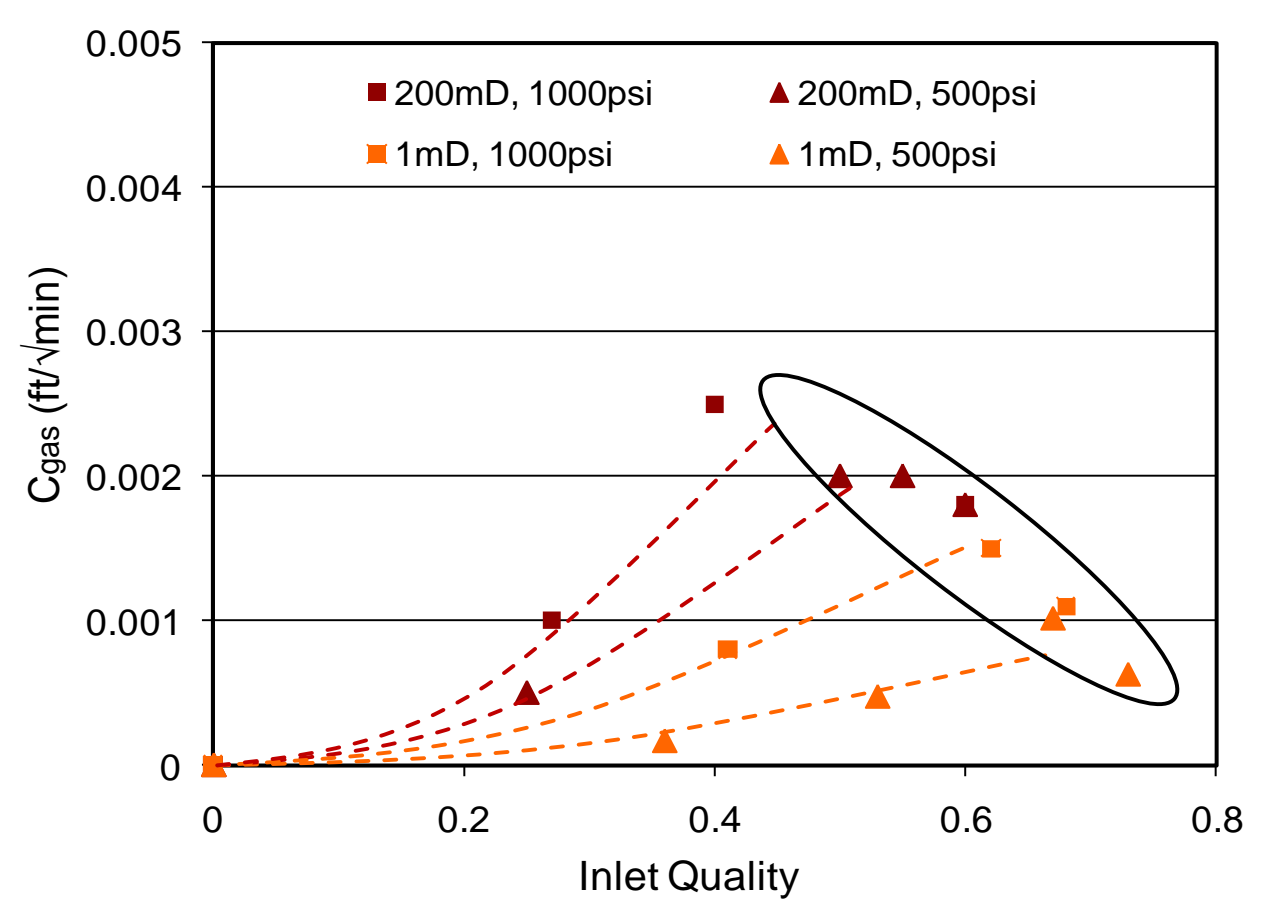

Figure 5.10: Effect of foam quality on the gas leak-off coefficient.

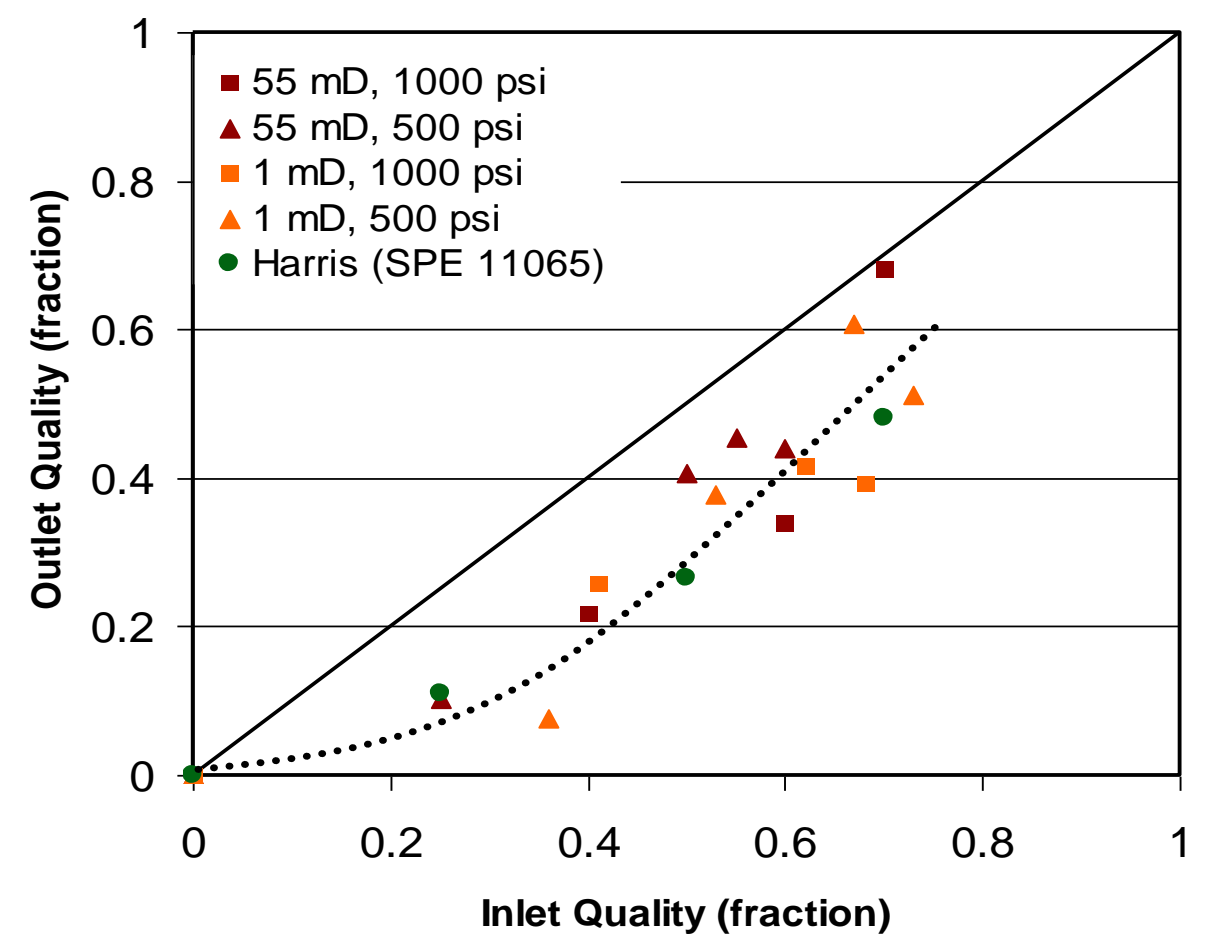

Figure 5.11: Outlet composition enriched in the liquid phase as the result of filtration. 


\section{Chapter 6: Return Permeability Results}

\subsection{Linear Gel Results}

To properly capture the fluid-loss behavior of linear gels at early times, core samples were fully presaturated with brine and the absolute permeability to brine was measured. Since no gas was introduced in the core before or during the experiment, a second brine flood was performed after the leak-off test in the opposite direction of the effluent. This second measurement gives the permeability to brine during flowback, which directly measures the fracturing fluid-induced damage.

The ratio of the damaged to initial permeability is given in Figure 6.1 for several linear gel tests. Regardless of the testing conditions, the return permeability ratio ranges from 12 to $26 \%$ with an average value of $18 \%$. This significant damage results from: (1) the incomplete removal of the viscous fluid that has invaded the core sample, (2) the external filter-cake resistance, and (3) the deposition of polymer residue in the pore space. Our regain permeability data compare well with the data published by McGowen and Vitthal (1996) and Parker et al. (1994). In McGowen and Vitthal (1996), the authors reported values of regain permeability ranging from 5.8 to $17 \%$ on $120-\mathrm{mD}$ cores. The regain permeability tests were performed after leak-off tests conducted with a 70 lbm/Mgal linear guar at 180F. In Table 2 of Parker et al. (1994), the regain permeability is about $7 \%$ under similar conditions. These values are lower than the one we measured but the polymer loading was significantly higher in their experiments. It should also be noted that the reported regain permeability depends on the core length. Even though most of the pressure drop occurs near the core inlet (where the external filter cake is), the reported pressure drop is actually averaged along a given core length. We encourage the

reader to pay attention to this detail when comparing regain permeability data. The 
comparison shows that the damage associated with the use of a linear gel is quite significant, with a decrease in permeability of about one order of magnitude.

\subsection{NitRogen FOAM RESULTS}

Foam return permeability tests were based on a comparison between the relative permeability to nitrogen before and after the leak-off test. Figure 6.2 shows return permeability results corresponding to various nitrogen foam tests. The relative gas permeability during flowback was consistently higher than the initial relative gas permeability. This observation does not imply that the absolute permeability of the core increased. Rather, it indicates that the gas saturation increased, and so did the relative permeability to gas. Under the given fracturing conditions, the energized fluid stimulated the invaded zone. Our results show that the fracturing-induced damage is minimal, and is much lower than the damage associated with linear gels. These observations are consistent with the findings of Harris (1985), who reported regain permeabilities of about $90 \%$ associated with the use of nitrogen-HPG foams. Both studies establish that the damage associated with foams is minimal.

The above observation is particularly important in formations in which water blocking is an issue (low permeability formations with small drawdown). The increase in the gas saturation in the invaded zone improves the ability to flow-back gas. It also enhances the clean-up of the formation. To properly quantify the fluid-induced damage, the initial permeability to gas should have been carefully measured at the true residual water saturation. 


\subsection{EXPERIMENTAL LIMITATIONS}

Based on the analysis of the results shown in this report, we identified a couple of experimental limitations that should be addressed in future studies. First, the initial water saturation of the core may influence the leak-off rate at early times. Preliminary results conducted in our laboratories have revealed that an increase of the initial water saturation does not impact the liquid leak-off but does lower the initial gas leak-off rate. This observation could explain some of the early discrepancies noticed in the gas leak-off rates presented in Figures 5.7 and 5.8. Furthermore, the comparison of the initial and regain permeabilities is affected by the initial water saturation. This can introduce some bias when performing a round-robin fluid sensitivity study. The authors encourage the reader to carefully consider the potential changes in water saturation when analyzing leak-off and regain permeability data.

As shown in Figure 5.10, the gas leak-off was found to be somewhat erratic at high foam qualities (above 60\%). It remains unclear whether this observation is to be related to the sharp increase in fluid viscosity at high foam qualities. Performing tests at high foam qualities can be a challenging task. Care should be taken when circulating high-quality foams since the foam may degrade over time. The foam integrity probably affects the multi-phase leak-off. Two foams that exhibit similar quality may behave differently over time depending on their stability. We would recommend performing an inspection of the bubble size distribution during the leak-off test. Then, the bubble size distribution might be related to the pore size distribution to better understand the physics behind the filtration process occurring at the core face.

The leak-off and regain permeability data presented here correspond to tests performed with an outlet pressure set to the atmospheric pressure. Tests performed at 
higher backpressures have shown some discrepancies over time. Indeed, a small pressure drop (a few psi) within the backpressure regulator results in a large volume of gas released at atmospheric conditions. This negatively affects the quality of the leak-off data over time. Highly accurate backpressure regulators are recommended when conducting multi-phase leak-off experiments.

For single-phase leak-off tests with linear gels, we found that the leak-off is not affected by the absolute pressure but only by the pressure drop across the core. However, the multi-phase leak-off is suspected to be dependent on the absolute pressure, as well as on the pressure drop. In other words, a test conducted with an inlet pressure of $1500 \mathrm{psi}$ and a backpressure of 500 psi may yield different results than a test conducted with an inlet pressure of $1000 \mathrm{psi}$ and a backpressure set to the atmospheric pressure. 


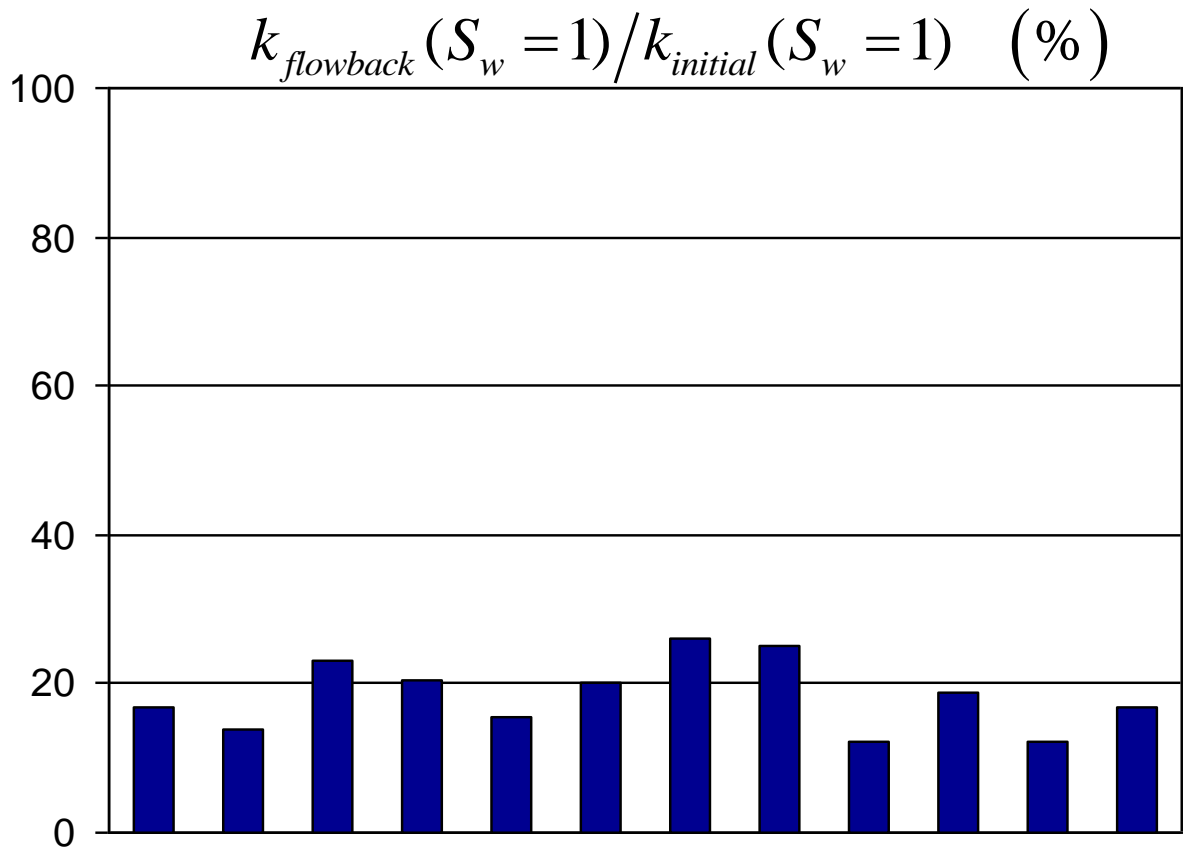

Figure 6.1: Return permeability results for linear guar gel experiments.

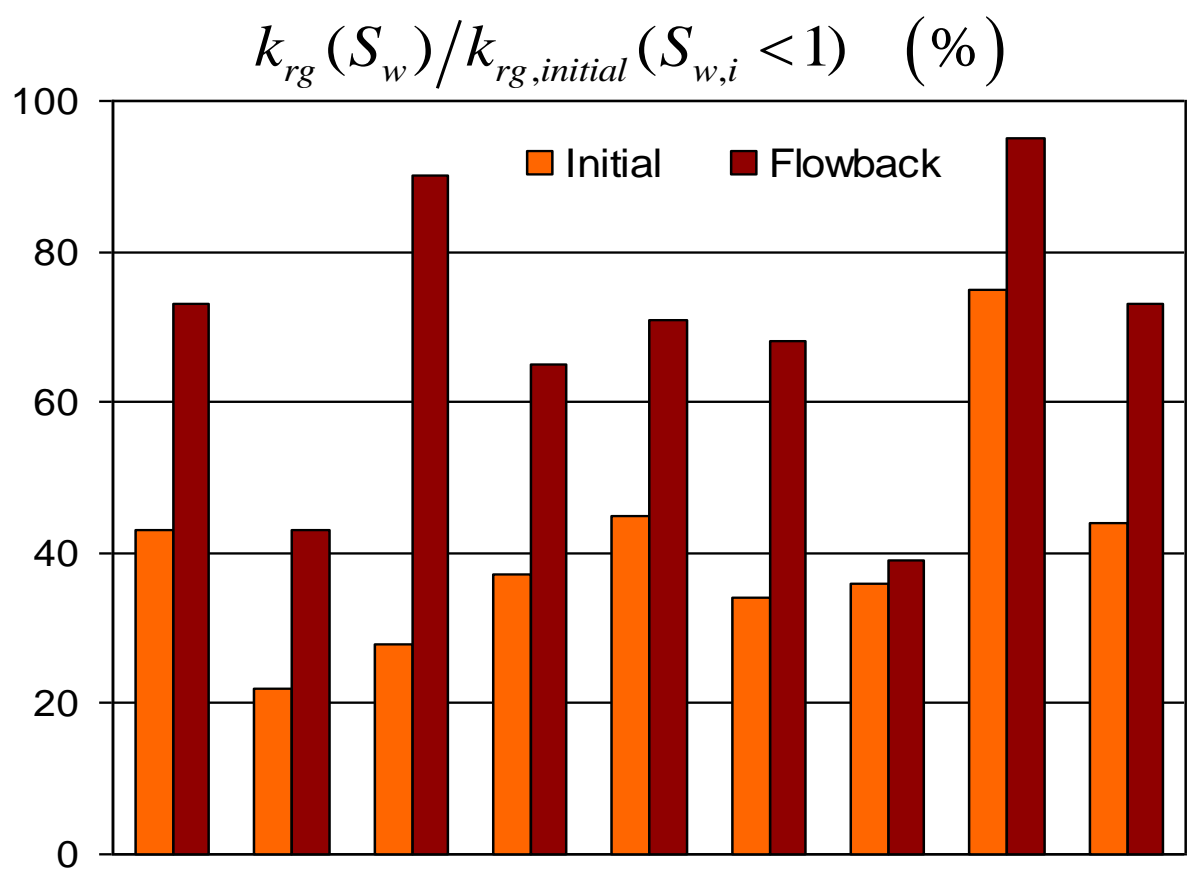

Figure 6.2: Return permeability results for $\mathrm{N}_{2}$ foam experiments. 


\section{Chapter 7: Conclusions and Future Work}

\subsection{Conclusions}

This report presents the first systematic experimental study of multi-phase fluidloss for fracturing fluids under dynamic conditions. We introduce a new experimental apparatus with the unique capability of combining foam rheology and dynamic leak-off measurements over time.

Our results show good agreement with the findings of McGowen and Vitthal (1996), who performed dynamic leak-off tests on linear gels, and the findings of Harris (1985), who performed semi-static leak-off tests on nitrogen foams. Table 7.1 compiles the sensitivity analysis for each parameter evaluated in this study. The leak-off tests presented here were conducted at ambient temperature and with a back pressure set to zero. If the foam leak-off results of this study may not be quantitatively correct under reservoir conditions, the underlying mechanisms of leak-off and the following trends and conclusions should remain valid:

1. At early times, the fluid-loss of linear gels is dominated by internal invasion. Therefore, the fluid-loss is highly sensitive to the core permeability and to the filtration pressure and is moderately sensitive to the gel loading.

2. At later times, the fluid-loss of linear gels is dominated by the external filter-cake. The leak-off coefficient appears to be sensitive to the core permeability and slightly sensitive to the shear rate. However, it is not sensitive to the filtration pressure or to the polymer loading.

3. Nitrogen foams containing polymers exhibit wall-building behavior and form an external filter-cake. 
4. Nitrogen foams show leak-off for both aqueous and gaseous phases at different rates. Even though the nitrogen solubility is negligible, the gas phase does leakoff into the invaded zone. As shown by Friehauf and Sharma (2010), this ability of the gas to leak-off has a critical effect on fracture geometry and fracture design for energized fractures.

5. The use of foams greatly improves the fluid-loss control properties of linear gels. This is particularly true in high permeability formations where spurt-loss may be considerable with linear gels.

6. At early times, both the gas and the liquid fluid-losses are sensitive to the core permeability and to the filtration pressure but to a lesser extent than with linear gels. The foam quality also impacts the fluid-loss.

7. At later times, the liquid and gas leak-off coefficients depend on the core permeability, the filtration pressure and the foam quality.

8. High-quality foams provide a slight improvement over lower quality foams (0.30.5), as they further reduce the liquid leak-off. However, it is still unclear whether the gas leak-off is reduced at high foam quality.

9. In terms of fracture-induced damage, foams greatly outperform linear gels. First, foams show limited invasion of the damaging liquid phase. Second, the gas component leaking-off into the invaded zone increases the gas saturation around the fracture, thereby enhancing the ability of the gas to flow back. 


\subsection{FUTURE WORK}

Successful design of energized fracturing treatments requires reliable foam rheology and foam leak-off data that can be used in a compositional fracturing simulator. Based on the experimental data, empirical correlations can be derived to predict the ability of the gas and the liquid phases to leak-off. This report sets the stage for future experimental studies with foam fluids. Future leak-off studies should address the following:

1. The behavior of gas leak-off at high quality is not very clear at this stage. It would be very beneficial to obtain more leak-off data at qualities higher than 0.7 .

2. The lowest rock permeability we used was $1 \mathrm{mD}$. There is currently a significant push for using foams in low-permeability plays but our leak-off data are not directly applicable to those low-permeability reservoirs.

3. The study should be enlarged to $\mathrm{CO}_{2}$ foam fluids. Harris (1987) showed that $\mathrm{N}_{2}$ and $\mathrm{CO}_{2}$ have very similar leak-off properties but more data should confirm or invalidate this observation.

4. Foam leak-off and foam rheology are very dependent on the choice of base-fluid formulation and foaming agent. This report only contains linear guar base-fluids. There are numerous base-fluid formulations (cross-linked, visco-elastic surfactants, etc.) and foaming agents to be investigated.

5. Foam leak-off measurements should be performed at higher absolute pressure to investigate the impact of gas expansion occurring in the core.

6. The impact of initial water saturation on both leak-off and regain permeability should be investigated. 
Finally, these multi-phase leak-off data are only useful if they can be implemented in a compositional fracturing simulator. Gas leak-off being usually lower than liquid leak-off, the fluid remaining in the fracture tends to be enriched in the liquid phase. This behavior cannot be captured by a traditional single-phase hydraulic fracturing simulator, which assigns a given leak-off rate to the entire fluid. The development of such a three-dimensional compositional fracturing simulator is under progress at the University of Texas at Austin. 
Table 7.1: Effect of various parameters on fluid-loss.

\begin{tabular}{|c|c|c|c|c|c|c|}
\hline & \multicolumn{2}{|c|}{ Linear Gels } & \multicolumn{4}{|c|}{ Nitrogen Foams } \\
\hline & Spurt-loss & $\mathrm{Cw}$ (liquid) & Spurt-loss (liquid) & Spurt-loss (gas) & $\mathrm{Cw}$ (liquid) & $\mathrm{Cw}$ (gas) \\
\hline Pressure & ++ & $=$ & ++ & ++ & + & + \\
\hline Permeability & +++ & ++ & +++ & +++ & ++ & ++ \\
\hline Shear Rate & + & $=$ & / & I & / & / \\
\hline Gel Loading & + & $=$ & l & l & l & l \\
\hline Foam Quality & N/A & N/A & --- & ++ & -- & ++ \\
\hline
\end{tabular}

(A sign "+/-" means that the volume of effluent increases/decreases as the parameter increases; "=” means that the effect is negligible; "/” means that the effect has not been investigated yet.) 


\section{Nomenclature}

\begin{tabular}{|c|c|c|}
\hline$A_{c}$ & $=$ & Core cross-sectional area, $\mathrm{L}^{2}, \mathrm{~cm}^{2}$ \\
\hline$C_{1}$ & $=$ & Empirical correlation factor from Reidenbach et al. (1986) \\
\hline$C_{w}$ & $=$ & Wall-building leak-off coefficient, $\mathrm{L} / \sqrt{ } \mathrm{T}, \mathrm{ft} / \sqrt{ } \min$ \\
\hline$k$ & $=$ & Rock permeability, $\mathrm{L}^{2}, \mathrm{mD}$ \\
\hline$K_{0}$ & $=$ & Herschel-Bulkley consistency index of base-fluid, $\mathrm{NT}^{\mathrm{n}} / \mathrm{L}^{2}, \mathrm{lbf}-\mathrm{sec}^{\mathrm{n}} / \mathrm{ft}^{2}$ \\
\hline$K_{\text {foam }}$ & $=$ & Herschel-Bulkley consistency index of foam, $\mathrm{NT}^{\mathrm{n}} / \mathrm{L}^{2}, \mathrm{lbf}-\mathrm{sec}^{\mathrm{n}} / \mathrm{ft}^{2}$ \\
\hline$m$ & $=$ & Slope of an experimental plot, $\mathrm{L}^{3} / \sqrt{\mathrm{T}}, \mathrm{cm}^{3} / \sqrt{\min }$ \\
\hline$n_{0}$ & $=$ & Herschel-Bulkley flow behavior index of base-fluid \\
\hline$n_{\text {foam }}$ & $=$ & Herschel-Bulkley flow behavior index of foam \\
\hline$t$ & $=$ & Time, $\mathrm{T}$, min \\
\hline$V$ & $=$ & Volume of effluent collected at the core outlet, $\mathrm{L}^{3}, \mathrm{~cm}^{3}$ \\
\hline$V_{S L}$ & $=$ & Spurt-loss volume, $\mathrm{L}^{3}, \mathrm{~cm}^{3}$ \\
\hline$\gamma$ & $=$ & Shear rate, $\mathrm{T}^{-1}, \mathrm{~s}^{-1}$ \\
\hline$\Gamma$ & $=$ & Foam quality (gas volume fraction) \\
\hline$\Delta P$ & $=$ & Pressure drop across the core, $\mathrm{N} / \mathrm{L}^{2}$, psi \\
\hline$\tau_{\text {foam }}$ & $=$ & Yield stress of foam, N/L $\mathrm{L}^{2}, \mathrm{lbf} / \mathrm{ft}^{2}$ \\
\hline$\mu$ & $=$ & Viscosity, NT/L ${ }^{2}, c p$ \\
\hline$\mu_{o}$ & $=$ & Base-fluid viscosity, NT/L ${ }^{2}, c p$ \\
\hline
\end{tabular}




\section{References}

Burke, L.H. and Nevison, G.W., 2011. Improved Unconventional Gas Recovery With Energized Fracturing Fluids: Montney Example. Paper SPE 149344 presented at the SPE Eastern Regional Meeting held in Colombus, Ohio, USA, 17-19 August 2011.

Economides, M.J. and Nolte, K.G., 2000. Reservoir Stimulation. John Wiley \& Sons, LTD.

Elbel, J.L., Navarrete, R.C., and Poe, B.D., 1995. Production Effects of Fluid Loss in Fracturing High-Permeability Formations. Paper SPE 30098 presented at the European Formation Damage Conference held in The Hague, The Netherlands, May 15-16, 1995.

Ettinger, R. and Radke, C., 1992. Influence of Texture on Steady Foam Flow in Berea Sandstone. SPE Res Eng, 7 (1):83-90.

Friehauf, K.E. and Sharma, M.M., 2009. Fluid selection for Energized Hydraulic Fractures. Paper SPE 124361 presented at the SPE Annual Technical Conference and Exhibition, 4-7 October 2009, New Orleans, Louisiana.

Friehauf, K.E., Suri, A., and Sharma, M.M., 2010. A Simple and Accurate Model for Well Productivity for Hydraulically Fractured Wells. SPE Prod \& Op 25 (4): $453-$ 460. SPE 129264-PA.

Gabris S. and Taylor J., 1986. The Utility of $\mathrm{CO}_{2}$ as an Energizing Component for Fracturing Fluids. SPE Prod Eng, 1 (5): 351-358. SPE 13794-PA.

Grundman, S.R. and Lord, D.L., 1983. Foam Stimulation. J Pet Technol 35 (3): 597-602. SPE 9754-PA.

Harris, P.C., 1985. Dynamic Fluid-Loss Characteristics of Nitrogen Foam Fracturing Fluids. J Pet Technol 37 (11): 1847-1852. SPE 11065-PA. 
Harris, P.C., 1987. Dynamic Fluid-Loss Characteristics of $\mathrm{CO}_{2}$-Foam Fracturing Fluids. SPE Prod Eng 2 (2): 89-94. SPE 13180-PA.

Hutchins, R.D. and Miller, M.J., 2005. A Circulating-Foam Loop for Evaluating Foam at Conditions of Use. SPE Prod \& Fac, 20 (4): 286-294. SPE 80242-PA.

Jiao, D. and Sharma M.M., 1992. Formation Damage due to Static and Dynamic Filtration of Water-Based Muds. Paper SPE 23823 presented at the SPE Intl. Symposium on Formation Damage Control held in Lafayette, Louisiana, February 26-27, 1992.

Khade, K. and Shah, S., 2004. New Rheological Correlations for Guar Foam Fluids. SPE Prod \& Fac, 19 (2): 77-85. SPE 88032-PA.

King, G., 1986. Foam and Nitrified Fluid Treatments-Stimulation Techniques and More. This paper is based on a speech presented as a Distinguished Lecture during the 1985-1986 season. SPE 14477.

Kovscek, A. and Radke, C., 1994. Foams: Fundamentals and Applications in the Petroleum Industry, Schramm, L., Editor, American Chemical Society, Washington D.C.

Mazza, R.L., 2001. Liquid-Free $\mathrm{CO}_{2} /$ Sand Stimulations: An Overlooked Technology Production Update. Paper SPE 72383 presented at the SPE Eastern Regional Meeting held in Canton, Ohio, USA, 17-19 October 2001.

McGowen, J.M and Vitthal, S., 1996. Fracturing-Fluid Leakoff Under Dynamic Conditions Part 1: Development of a realistic Laboratory testing Procedure. Paper SPE 36492 presented at the 1996 Annual Technical Conference held in Denver, Colorado, 6-9 October 1996.

McGowen, J.M and Vitthal, S., 1996. Fracturing-Fluid Leakoff Under Dynamic Conditions Part 2: Effect of Shear Rate, Permeability and Pressure. Paper SPE 36493 presented at the 1996 Annual Technical Conference held in Denver, Colorado, 6-9 October 1996. 
Navarrete, R.C., Cawiezel, K.E., and Constien, V.G., 1996. Dynamic Fluid-Loss in Hydraulic Fracturing Under Realisitc Shear Conditions in High-Permeability Rocks. SPE Prod \& Fac 11 (3): 138-143. SPE 28529-PA.

Parker, M.A. et al., 1994. Hydraulic Fracturing of High-Permeability Formations To Overcome Damage. Paper SPE 27378 presented at SPE Formation Damage Control Symposium held in Lafayette, Louisiana, USA, 7-10 February 1994.

Penny, G.S. and Conway, M.W., 1989. Recent Advances in Hydraulic Fracturing. Monograph Series, SPE, Richardson, Texas 1: 147-176.

Penny, G.S., Conway, M.W, and Lee, W., 1985. Control and Modeling of Fluid Leakoff During Hydraulic Fracturing. J Pet Technol 37 (6): 1071-1081. SPE 12486-PA.

Ribeiro, L.H., and Sharma, M.M, 2011. Multi-Phase Fluid-Loss Properties and Return Permeability of Energized Fracturing Fluids. Paper SPE 139622 presented at the SPE Hydraulic Fracturing Technology Conference held in The Woodlands, Texas, USA, 24-26 January, 2011.

Reidenbach, V.G., Harris, P.C., Lee, Y.N., and Lord, D.L., 1986. Rheological Study of Foam Fracturing Fluids Using Nitrogen and Carbon Dioxide. SPE Prod Eng 1 (1): 31-41. SPE 12026-PA.

Wendorff, C.L. and Ainley, B.R., 1981. Massive Hydraulic Fracturing of HighTemperature Wells with Stable Frac Foams. Paper SPE 10257 presented at the Fall Technical Conference and Exhibition, 5-7 October, San Antonio, Texas.

Yi, T. and Peden, J.M., 1994. A comprehensive Model of Fluid-Loss in Hydraulic Fracturing. SPE Prod \& Fac 9 (4): 267-272. SPE 25493-PA. 